\title{
A Comprehensive Small Interfering RNA Screen Identifies Signaling Pathways Required for Gephyrin Clustering
}

\author{
Jennifer Wuchter, ${ }^{1}$ Simone Beuter, ${ }^{1}$ Fridolin Treindl, ${ }^{2}$ Thoralf Herrmann, ${ }^{3}$ Günther Zeck, ${ }^{3}$ Markus F. Templin, ${ }^{2}$ \\ and Hansjürgen Volkmer ${ }^{1}$ \\ Departments of ${ }^{1}$ Molecular Biology and ${ }^{2}$ Biochemistry and Protein Profiling, and ${ }^{3}$ Research Group Neurochip, Naturwissenschaftliches und Medizinisches \\ Institut an der Universität Tübingen, 72770 Reutlingen, Germany
}

\begin{abstract}
The postsynaptic scaffold protein gephyrin is clustered at inhibitory synapses and serves for the stabilization of $\mathrm{GABA}_{\mathrm{A}}$ receptors. Here, a comprehensive kinome-wide siRNA screen in a human HeLa cell-based model for gephyrin clustering was used to identify candidate protein kinases implicated in the stabilization of gephyrin clusters. As a result, 12 hits were identified including FGFR1 (FGF receptor 1), TrkB, and TrkC as well as components of the MAPK and mammalian target of rapamycin (mTOR) pathways. For confirmation, the impact of these hits on gephyrin clustering was analyzed in rat primary hippocampal neurons. We found that brain-derived neurotrophic factor (BDNF) acts on gephyrin clustering through MAPK signaling, and this process may be controlled by the MAPK signaling antagonist sprouty2. BDNF signaling through phosphatidylinositol 3-kinase (PI3K)-Akt also activates mTOR and represses GSK3 $\beta$, which was previously shown to reduce gephyrin clustering. Gephyrin is associated with inactive mTOR and becomes released upon BDNFdependent mTOR activation. In primary neurons, a reduction in the number of gephyrin clusters due to manipulation of the BDNFmTOR signaling is associated with reduced $\mathrm{GABA}_{\mathrm{A}}$ receptor clustering, suggesting functional impairment of GABA signaling. Accordingly, application of the mTOR antagonist rapamycin leads to disinhibition of neuronal networks as measured on microelectrode arrays. In conclusion, we provide evidence that BDNF regulates gephyrin clustering via MAPK as well as PI3K-Akt-mTOR signaling.
\end{abstract}

\section{Introduction}

Synaptic connectivity in neuronal networks relies on the development of excitatory and inhibitory synapses. However, once the network is established, further mechanisms of plasticity may control the number and efficacy of presynaptic and postsynaptic specializations (Jin et al., 2011). Postsynaptic scaffolding molecules like PSD-95 in the case of excitatory synapses and gephyrin in the case of inhibitory synapses assemble neurotransmitter receptors in the postsynaptic membrane and thereby contribute to the dynamics or stabilization of synapses (Kim and Sheng, 2004; Fritschy et al., 2008; Luscher et al., 2011; Xu, 2011). In the case of inhibitory synapses, ablation of the gephyrin gene disassembles $\mathrm{GABA}_{\mathrm{A}}$ receptors and reduces the number of GABAergic synapses (Kneussel et al., 1999; Jacob et al., 2005; Yu et al., 2007). The transport of gephyrin to the submembrane compartment de-

Received March 14, 2012; revised Aug. 2, 2012; accepted Aug. 20, 2012.

Author contributions: G.Z., M.T., and H.V. designed research; J.W., S.B., F.T., and T.H. performed research; J.W., S.B., F.T., T.H., G.Z., and M.T. analyzed data; J.W. and H.V. wrote the paper.

Part of this work was supported by Bundesministerium für Bildung und Forschung (BMBF) Grant 0315512B (H.V.) and BMBF Grant 0312038 (T.H., G.Z.). We are grateful to Christine Dürr for technical assistance. We thank Martin Kriebel for helpful discussions. The sprouty2 expression vector was a generous gift provided by Lars Klimaschewski and Barbara Hausott. Plasmids pDONR223-MAP2K2, LZRS-Mek2-K101A, and LZRS-Mek2-KW71 were supplied by Paul Khavari and David Root, and plasmids HA GSK3 $\beta$ S9A pcDNA3 and myrAkt $\Delta 4-129$ by Jim Woodgett and Richard Roth (via addgene.org).

The authors declare no competing financial interests.

Correspondence should be addressed to Hansjürgen Volkmer, Department of Molecular Biology, Naturwissenschaftliches und Medizinisches Institut an der Universität Tübingen, Markwiesenstrasse 55, 72770 Reutlingen, Germany. E-mail:volkmer@nmi.de.

DOI:10.1523/JNEUROSCI.1261-12.2012

Copyright $\odot 2012$ the authors $\quad 0270-6474 / 12 / 3214821-14 \$ 15.00 / 0$ pends on its association with collybistin II, a GEF (GTP exchange factor) specific for cdc42 (Kins et al., 2000; Harvey et al., 2004; Xiang et al., 2006; Saiepour et al., 2010). A contribution of the GTPase cdc42 to gephyrin clustering remains controversial (Reddy-Alla et al., 2010; Tyagarajan et al., 2011b). Gephyrin clusters may be further stabilized in the submembrane compartment via interactions with the transmembrane receptor neuroligin-2 (Graf et al., 2004; Poulopoulos et al., 2009). However, signaling cascades controlling membrane translocation of gephyrin remain elusive. One upstream mechanism may be represented by the interaction between the receptor tyrosine kinase (RTK) tropomyosin-related kinase $\mathrm{B}(\mathrm{TrkB})$ and its ligand brainderived neurotrophic factor (BDNF). BDNF contributes to the formation and maturation of GABAergic synapses (Bao et al., 1999; Seil and Drake-Baumann, 2000). The BDNF receptor TrkB was shown to be required for gephyrin clustering (Chen et al., 2011). Fibroblast growth factor receptor 1 (FGFR1) has also been shown to account for the control of gephyrin clusters at the axon initial segment after interaction with the cell adhesion molecule neurofascin (Kriebel et al., 2011). These findings suggest a general involvement of RTK signaling for gephyrin clustering.

For a comprehensive understanding of contributing signaling pathways, we undertook a genome-wide siRNA screen to identify protein kinases implicated in gephyrin clustering. Hits found include the RTKs TrkB, TrkC, and FGFR1 as well as components of mitogen-activated protein kinase (MAPK) and phosphatidylinositol 3-kinase (PI3K)-Akt pathways that are connected to RTK signaling. The impact of BDNF signaling on gephyrin clustering was corroborated in primary neurons. The experiments reveal a 
novel mechanism for the control of gephyrin clustering including the activation of mTOR via PI3K-Akt signaling. Activated mTOR shows reduced interaction with gephyrin, which correlates with increased gephyrin clustering.

\section{Materials and Methods}

HeLa cell-based siRNA screen. Cultivation and transfection of HeLa cells was performed essentially as described previously (Kriebel et al., 2011). A total of 710 individual siRNAs targeting all known 518 protein kinases plus 192 protein kinase-associated proteins (Silencer Select Human Kinase siRNA Library V4; Invitrogen) was transfected into HeLa cells. The library consisted of 2130 different siRNAs with three independent siRNAs for each of the 710 targets. In an initial experiment, a first siRNA was applied for each of all 710 targets. For each of the 12 hits obtained, the experiment was repeated with a second siRNA to rule out off-target effects (see Fig. $1 D$ ). In case that the second siRNA did not reproduce the effects of the first siRNA, a third siRNA was applied. A gene was defined as a hit if at least two independent siRNAs resulted in a significant decrease of the gephyrin cluster size compared with the positive control (EGFP-gephyrin, $\mathrm{CBII} \mathrm{SH}_{3-}$, neurofascin NF166) in two independent experiments. Confirmation of trkB and FGFR1 as hits was performed by three independent experiments (see Fig. 2). siRNA was combined with the plasmids pEGFP-C2/gephyrin (kindly provided by $\mathrm{H}$. Betz and G. O'Sullivan, Frankfurt, Germany), pRK5myc/collybistin $\mathrm{SH}_{3-}$ (a gift from R. J. Harvey, London, UK), and neurofascin NF166 (Pruss et al., 2006) (0.3 $\mu \mathrm{g}$ each, equal total plasmid concentrations were used) in OptiMEM (Invitrogen) before addition of the Lipofectamine 2000/OptiMEM solution (final concentration of siRNA, $26.6 \mathrm{~nm}$ ). After 3 d cultivation, EGFP-gephyrin clustering was determined by visual inspection in blinded trials.

Transfection of primary neurons. Primary hippocampal or cortical neurons were prepared from E17 rat embryos of either sex as described previously (Kriebel et al., 2011) and cultivated at a density of $1.8 \times 10^{5}$ cells $/ \mathrm{cm}^{2}$ for 96 -well plates, or of $2 \times 10^{5} \mathrm{cells} / \mathrm{cm}^{2}$ in 12 -well plates, respectively. Both cortical and hippocampal neurons were shown to respond to BDNF treatment by activation of MAPK or PI3K-Akt signaling (Hetman et al., 1999; Kumar et al., 2005). For the transient transfection of hippocampal neurons, $500 \mathrm{ng}$ of plasmid DNA or siRNA (final concentration, $26.6 \mathrm{~nm}$ ) were transfected using $1 \mu \mathrm{l}$ of Lipofectamine 2000 (Invitrogen) in $80 \mu \mathrm{l}$ of the plating medium. Neurons were transfected at DIV 10 and were fixed after 7 additional days of incubation. Plasmids used were as follows: pEGFP-N1 (Clontech), pcDNA3.1/sprouty2 (from Mus musculus; gift from L. Klimaschewski, Innsbruck, Austria), pEGFPN1/MEK2 wild-type, dominant-negative, and constitutively active variants are derived from pDONR223-MAP2K2, LZRS-Mek2-K101A, and LZRS-Mek2-KW71 (www.addgene.org; plasmids 23555, 21191, 21192). Inserts of MEK2 plasmids were subcloned into pEGFP-N1 vector using SacII and HpaI restriction enzymes. Constitutively active variants of GSK $3 \beta$ and Akt 1 were expressed by plasmids HA GSK3 $\beta$ S9A in pcDNA3 and myrAkt $\Delta 4-129$ (www.addgene.org; plasmids 14754, 10841). All plasmids were used at equal amounts. The following rat-specific siRNAs were used: siMEK2 (Applied Biosystems; siRNA ID s133009); siNTRK2 (TrkB) (Applied Biosystems; siRNA ID s128896). Inhibitors and recombinant proteins were dissolved in dimethylsulfoxide (DMSO) or water and added to hippocampal neurons (DIV 16) to final concentrations of $10 \mu \mathrm{M}$ for MEK2 inhibitor 1,4-diamino-2,3-dicyano-1,4-bis(2-aminophenylthio)butadiene (U0126) (Merck), $10 \mu \mathrm{M}$ for PI3K inhibitor 2-morpholin-4-yl-8-phenylchromen-4-one (LY294002) (Merck), 200 nM for mTOR inhibitor rapamycin (Merck), and $200 \mathrm{ng} / \mathrm{ml}$ for TrkB ligand BDNF (Sigma-Aldrich). Analyses were performed $24 \mathrm{~h}$ after addition of the reagents.

Amaxa Rat Neuron Nucleofector Kit (Lonza Group) was used to analyze endogenous expression levels of TrkB after siCTR or siTrkB transfection. A total of $5 \times 10^{6}$ cortical neurons per transfection was centrifuged at $150 \times \mathrm{g}$ after preparation, resuspended using $100 \mu \mathrm{l}$ of Nucleofection Reagent in the presence of $2 \mu \mathrm{g}$ of pmaxGFP plasmid as well as siRNA at a final concentration of $80 \mathrm{~nm}$. The suspension was then transferred to a cuvette for nucleofection (program G-013). Transfection efficiency was at $\sim 60 \%$ as roughly calculated by transfection of the GFP expression plasmid (pmaxGFP) as an indicator. The true transfection efficiency of siRNA is expected to be much higher. RNA preparation and quantitative RT-PCR were performed after $3 \mathrm{~d}$.

RNA preparation and RT-PCR analysis. Total RNA of transfected cortical neurons (DIV 3) was prepared using RNeasy Mini Kit (QIAGEN) according to manufacturer's guidelines. DNase digest as well as cDNA synthesis were performed according to manufacturer's instruction using RQ1 DNase (Promega) as well as M-MuLV reverse transcriptase (New England Biolabs). Quantitative real-time PCR (qRT-PCR) was performed on the 7500 Fast Real-Time PCR System (Applied Biosystems/ Invitrogen). The following assays were used: GAPDH (VIC/MGB), Rn01775763_g1; Ntrk2 (TrkB) (FAM), Rn 01441749_m1 (Applied Biosystems/Invitrogen)

Immunocytochemistry. For immunocytochemical analysis, the following antibodies were used: anti-gephyrin (mAb7a; 1:100; Synaptic Systems), anti-MAP2 (1:1000; Sigma-Aldrich), anti-PSD-95 (1:100; Cell Signaling Technology/New England Biolabs), and anti-GABA $\mathrm{A}_{\mathrm{A}}$ receptor $\gamma$-subunit (1:200; Synaptic Systems).

HeLa cells were fixed $3 \mathrm{~d}$ after transfection, and primary hippocampal neurons at DIV 17 using 4\% paraformaldehyde/PBS for $10 \mathrm{~min}$. After blocking and permeabilizing $(0.2 \%$ Triton X-100 in PBS containing $1 \times$ BMB blocking reagent; Roche), cells were incubated overnight at $4^{\circ} \mathrm{C}$ in primary antibody diluted in blocking solution. Subsequently, cells were washed three times using PBS before the secondary antibody (1:400; Cy3/Cy5-coupled goat anti-mouse respectively goat anti-rabbit; Dianova) was added for $1 \mathrm{~h}$ at room temperature. Nuclei were stained using Hoechst 33258 (1:1000; Sigma-Aldrich).

Immunoprecipitation and Western blot. For immunoprecipitation, primary cortical neurons were cultivated in 12-well plates for $17 \mathrm{~d}$. Neurons were then pretreated with rapamycin $(200 \mathrm{nM})$ or DMSO for $30 \mathrm{~min}$. Then BDNF was added to the culture at a final concentration of 200 $\mathrm{ng} / \mathrm{ml}$ for an additional $30 \mathrm{~min}$. For each treatment, 6-8 wells of a 12 -well plate were used and pooled at later stages. Cells were washed using ice-cold PBS, and then $50 \mu \mathrm{l}$ of IP-lysis buffer ( $10 \mathrm{~mm}$ Tris- $\mathrm{HCl}, \mathrm{pH}$ 7.5, $100 \mathrm{~mm} \mathrm{NaCl}, 10 \mathrm{~mm}$ EDTA, 0.5\% Triton X-100, 0.5\% desoxycholate) was added to each well and incubated for $10 \mathrm{~min}$ on ice. Using a cell scraper, the lysates were collected, pooled, and centrifuged for $10 \mathrm{~min}$ at $4^{\circ} \mathrm{C}$ at $16,000 \times g$ in an Eppendorf centrifuge. Protein concentrations were determined (BCA assay kit; Pierce/Thermo Fisher Scientific). A total of $600 \mu \mathrm{g}$ of total protein was mixed with the appropriate amount of anti-mTOR antibody (1:100; no. 2972; Cell Signaling Technology/New England Biolabs) and incubated at $4^{\circ} \mathrm{C}$ for at least $6 \mathrm{~h}$ on a rotating device. Subsequently, $25 \mu \mathrm{l}$ of a suspension $(50 \% \mathrm{v} / \mathrm{v})$ of protein A-Sepharose (Sigma-Aldrich) was added and incubated overnight at $4^{\circ} \mathrm{C}$ on a rotating device. The beads were then washed in five alternate steps of centrifugation and resuspension in lysis buffer. Samples of the lysates and of the immunoprecipitate were separated by SDS-PAGE and transferred to a nitrocellulose membrane by Western blotting. Detection was performed using horseradish peroxidase-coupled goat anti-rabbit secondary antibodies (Dianova), ECL substrate (GE Healthcare), and conventional development using $\mathrm{x}$-ray films (GE Healthcare). The following primary antibodies were used: anti-gephyrin (1:1000; Synaptic Systems) and anti-mTOR antibody (1:1000; no. 2983; Cell Signaling Technology/ New England Biolabs).

For analysis of cellular signaling, cortical neurons were plated on 12-well plates at a density of $2 \times 10^{5}$ cells $/ \mathrm{cm}^{2}$. At DIV 17, cells were pretreated for 30 min using DMSO, MEK2 inhibitor U0126, PI3K inhibitor LY294002, or mTOR inhibitor rapamycin. The cells were treated with TrkB ligand BDNF for $30 \mathrm{~min}$ before lysis using $80 \mu \mathrm{l}$ of 2D electrophoresis buffer (Rabilloud, 2009). Protein concentration in the lysates was determined using the Coomassie Plus Protein Assay (Pierce; Thermo Fisher Scientific); Western blotting was performed as described above. The primary antibodies were purchased from Cell Signaling Technology/New England Biolabs, except for the anti-GSK3 $\alpha / \beta$ pTyr279/Tyr216 antibody, which was purchased from Epitomics/BIOMOL and the anti- $\beta$-Actin antibody (Sigma-Aldrich). As secondary antibodies, IRDye800CW-conjugated goat anti-rabbit IgG and IRDye680-conjugated goat anti-mouse IgG (LI-COR) were used, and protein bands were recorded on an Odyssey Infrared Imaging System (LI-COR). Densitometric analysis of band intensities was performed using the gel ana- 

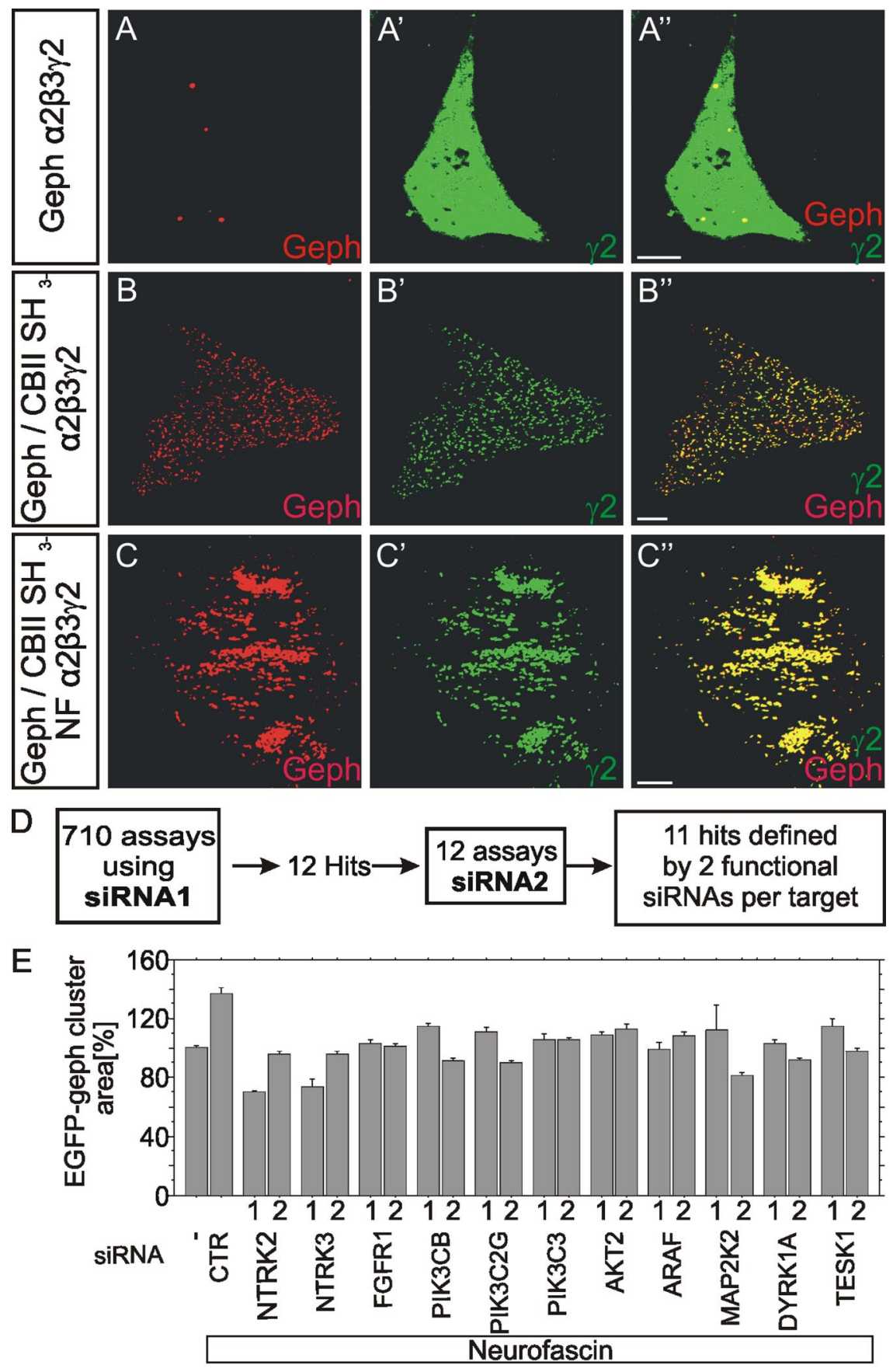

\begin{tabular}{|l|l|}
\hline \multicolumn{1}{|c|}{ Receptor Tyrosine Kinases } & \multicolumn{1}{|c|}{ MAPK pathway } \\
\hline $\begin{array}{l}\text { NTRK2 (trkB) } \\
\text { NTRK3 (trkC) } \\
\text { FGFR1 }\end{array}$ & ARAF (A-raf), \\
\hline \multicolumn{1}{|c|}{ PI3K-Akt pathway } & \\
\hline $\begin{array}{l}\text { PIK3CB (PI3K p110 subunit beta) } \\
\text { PIK3C2G (PI3K-C2-gamma) } \\
\text { PIK3C3 (PI3-kinase type 3) }\end{array}$ & \multicolumn{1}{|c|}{ Sprouty signalling } \\
AKT2 (Akt2) & TESK1 \\
\hline
\end{tabular}

Figure 1. A comprehensive siRNA screen in HeLa cells with gephyrin clustering as a readout. $A, B, C$, EGFP-gephyrin signal. $A^{\prime}$, $\boldsymbol{B}^{\prime}, \boldsymbol{C}^{\prime}, \mathrm{GABA} \mathrm{A}_{\mathrm{A}}$ receptor gamma2 subunit. $\boldsymbol{A}^{\prime \prime}, \boldsymbol{B}^{\prime \prime}, \boldsymbol{C}^{\prime}$, Merge of $\boldsymbol{A}, \boldsymbol{B}, \mathbf{C}$ and $\boldsymbol{A}^{\prime}, \boldsymbol{B}^{\prime}, \boldsymbol{C}^{\prime}$, respectively. Scale bars, $10 \mu \mathrm{m} . \boldsymbol{A}$, In addition to expression vectors for the GABA receptor subunits $\alpha 2, \beta 3$, and $\gamma 2$, HeLa cells were transfected with an EGFP-gephyrin expression lyzer function of ImageJ software (Wayne Rasband, National Institutes of Health, Bethesda, $\mathrm{MD})$; for densitometric analysis of the Western blots, the Multi Gauge software package (FujiFilm) was used.

Image acquisition, analysis, and statistical analysis. Confocal fluorescence images were acquired at $23^{\circ} \mathrm{C}$ using a Zeiss LSM510 Meta confocal microscope equipped with a $63 \times$ Plan-Apochromat oil-immersion objective (NA 1.4; Carl Zeiss). Single images of HeLa cells, and $Z$-stacks of primary hippocampal neurons were recorded. The images were processed and analyzed using Imaris software (Bitplane). Briefly, images of primary hippocampal neurons were analyzed with the Imaris software with the possibility of threedimensional reconstruction. A surface mask was built for the MAP2 or EGFP channel. This mask was used to build a new channel including all synaptic spots (gephyrin or PSD-95), which colocalized to the MAP2 or EGFP mask. Then a region of interest was built containing the first $20 \mu \mathrm{m}$ of a dendrite and another mask was built containing all synaptic spots in this area. As a result, Imaris software was able to give information about the size and number of spots in the constructed mask. All figures displaying primary hippocampal neurons are the result of Imaris rendered images. For HeLa cells, images were also processed using Imaris software, but only the surface of EGFP-gephyrin was calculated. Within each experiment, exposure time for image acquisition, and imaging settings for contrast, brightness, resolution, and threshold values were applied identically.

Statistical analysis were performed using StatView software (SAS Institute). A $t$ test or ANOVA analysis was performed: values of $p$ were as follows: ${ }^{\star} p<0.05,{ }^{\star *} p<0.01$, and ${ }^{* * *} p<0.001$. All experiments were performed at least three times independently of each other.

Electrophysiology and spike data analysis. Cortical neurons were prepared as described previously (Kriebel et al., 2011) and plated on a 60-channel microelectrode array (TiN; 200 $\mu \mathrm{m}$ electrode spacing; NMI TT). Extracellular recordings were obtained as described previously (Mazzoni et al., 2007). To avoid variabil-

vector alone or cotransfected with an EGFP-gephyrin expression vector together with a collybistin $\|_{\mathrm{SH}_{3}-}$ expression vector. While EGFP_ gephyrin forms intracellular aggregates as shown in $A$, coexpression of collybistin $\|_{{ }_{S H 3}}$ induces formation of gephyrin clusters in a submembrane compartment $(\boldsymbol{B})$. Furthertransfection ofneurofascin ( $($ induces largesubmembranedusters ofgephyrin. The siRNA screen was accomplished in the presence of neurofascin expression as exemplified in C to identify genes stabilizing gephyrin clusters, thus reverting the phenotype to a situation as shown in B.D, Schematic ovenview of the screening strategy conducted in Hela cells. $\boldsymbol{E}$, Quantification of gephyrin cluster size of all hits obtained in the siRNA screen. Controls are EGFP_ geph plus collybistin $\|_{\mathrm{SH}_{3}-}(-)$; EGFP-geph plus collybistin $\|_{\mathrm{SH}_{3}-}$ plus neurofascin plus siCTR (CTR). Cluster size was determined from $>1150$ gephyrin spots collected from 20 cells for each condition; $p<$ 0.0001 for all bars compared with (TR (ANOVA). Error bars represent SEM.F, Summary of hits sorted into distinct pathways. 
ity in the cultures of different ages, all control data were recorded at day 21 in vitro. All recordings following the application of rapamycin and additional control recordings were performed on DIV 24. The arrays were sealed with a semipermeable membrane that keeps the cultures sterile and allows for multiple recording sessions. Each culture was recorded for 10 min on DIV 21 and on DIV 24, respectively. Extracellular recordings of four cultures treated with rapamycin were additionally performed on DIV 22 and on DIV 23 to estimate whether the mean firing rate changes throughout the time interval investigated. Parallel extracellular recordings were obtained using a MEA-60 amplifier (bandpass, $0.3-3 \mathrm{kHz}$; sampling rate, $25 \mathrm{kHz}$ ) with MCRack (Multi Channel Systems MCS). The extracellular waveforms were assigned to single cells following spike sorting (MCRack) and Waveclus (Quiroga et al., 2004). The spike sorting fidelity was confirmed by inspection of the refractory period. Only properly sorted electrodes were considered for further analysis performed with Matlab (MathWorks).

\section{Results}

siRNA library screen for the

identification of protein kinases

involved in gephyrin clustering

For the identification of genes implicated in gephyrin clustering, a suitable assay system was developed to enable large-scale screening of siRNA libraries. HeLa cells expressing EGF$\mathrm{P}$-gephyrin as well as the collybistin isoform $\mathrm{CBII}_{\mathrm{SH} 3}$ - were used to study gephyrin clustering in a surrogate model (Harvey et al., 2004). Transfection of cells using an EGF$\mathrm{P}$-gephyrin construct in the absence of $\mathrm{CBII}_{\mathrm{SH} 3}-$ yields intracellular aggregates of EGFP-gephyrin while coexpressed $\mathrm{GABA}_{\mathrm{A}}$ receptors remain equally distributed at the cell surface (Fig. $1 A-A^{\prime \prime}$ ). Cotransfection of cells using EGFP-gephyrin and $\mathrm{CBII}_{\mathrm{SH} 3}-$ constructs results in the formation of submembrane gephyrin clusters that colocalize with $\mathrm{GABA}_{\mathrm{A}}$ receptors (Harvey et al., 2004; Kriebel et al., 2011) (Fig. $1 B-B^{\prime \prime}$ ). An siRNA library was to be screened for candidate sequences that reduce gephyrin clustering in the $\mathrm{HeLa}$ cell model. However, the small size of membrane-bound gephyrin clusters as well as the observed variability of cluster formation in individual cells precluded the reliable detection of changes in gephyrin clustering in a high-throughput format. We therefore decided to boost gephyrin clustering by coexpression of the cell adhesion molecule neurofascin, which induces considerable enlargement of gephyrin cluster size (Fig. 1C) (Kriebel et al., 2011). To rule out that neurofascin expression merely induces intracellular deposits of gephyrin rather than promoting enlarged submembrane gephyrin clusters, we analyzed the expression of
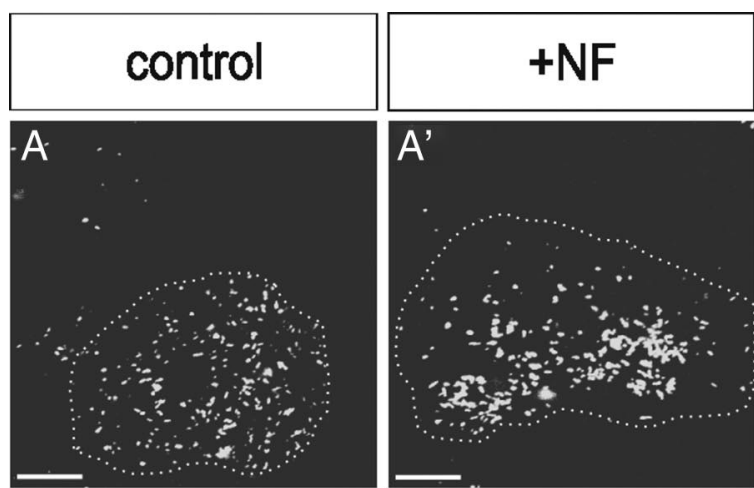

\section{+NF+ siCTR}
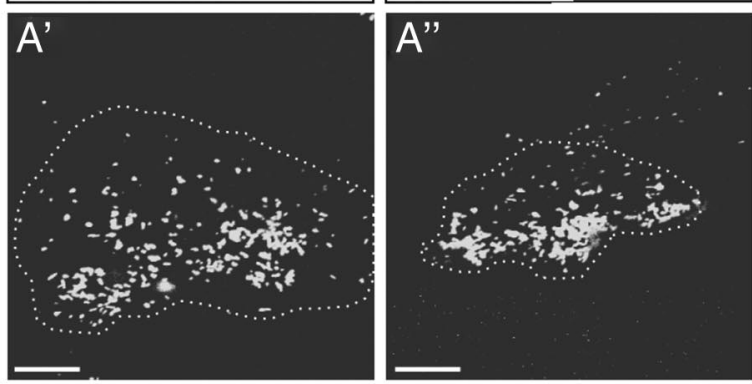

\section{B}
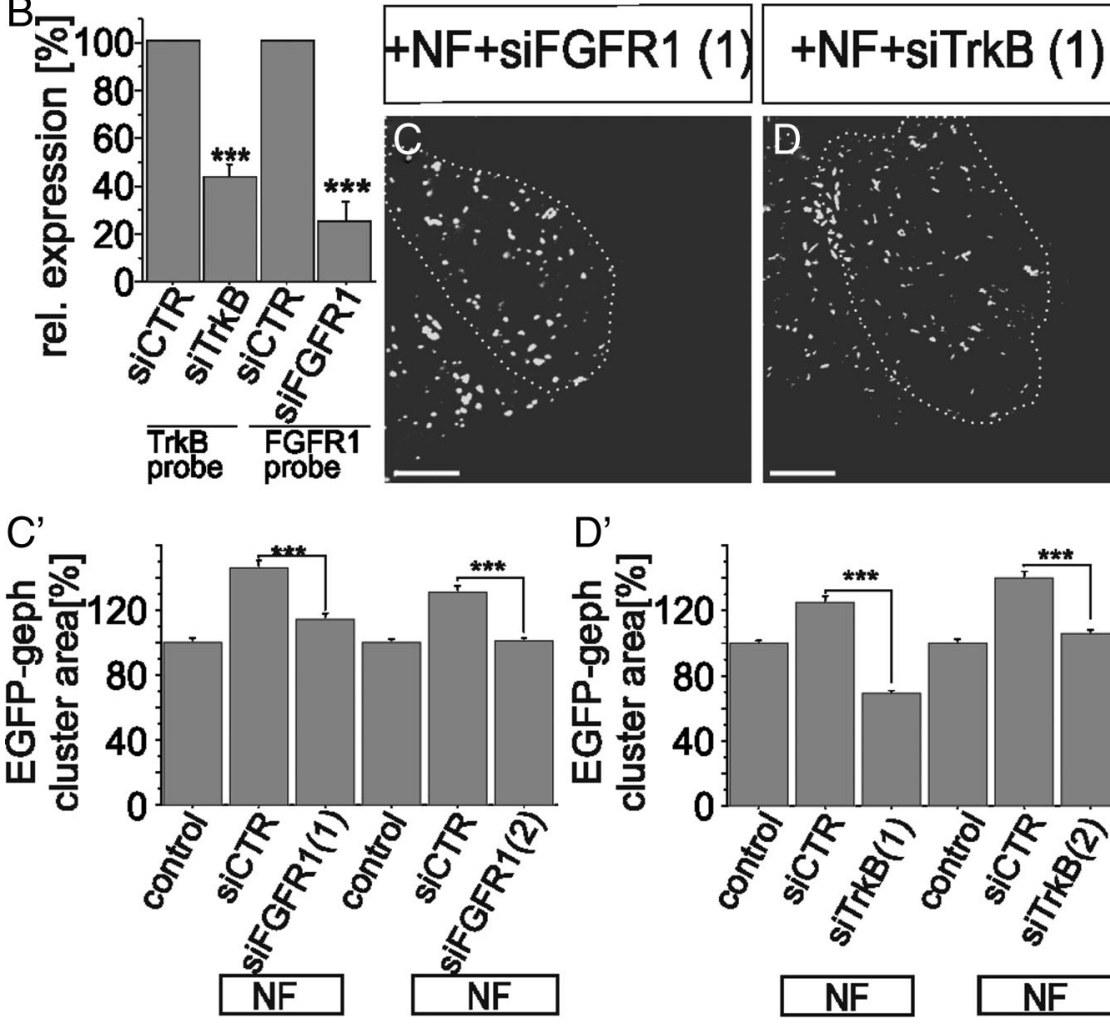

D'

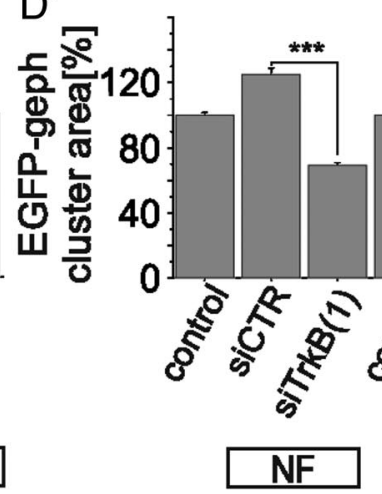

$\mathrm{F}$

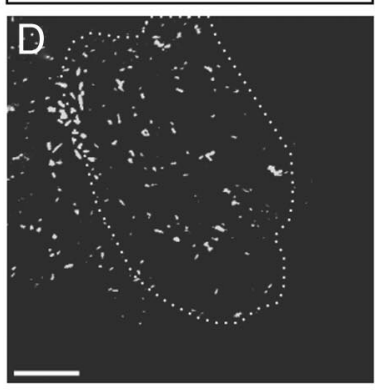

E
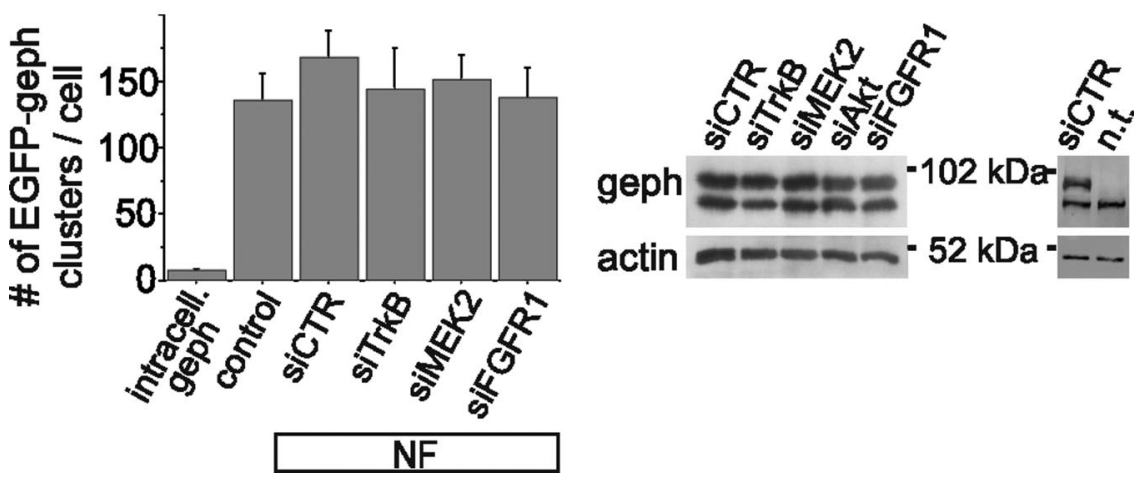

Figure 2. Knockdown of TrkB and FGFR1 impairs gephyrin clustering in HeLa cells. Expression constructs for EGFP-gephyrin and $\mathrm{CBII}_{\mathrm{SH} 3}$ - were cotransfected with further constructs as indicated. $A-A^{\prime \prime}$, Control siRNA does not decrease neurofascin-induced gephyrin clustering. B, Quantitative RT-PCRdemonstrating knockdown of trkB and FGFR1 mRNA levels aftertransfection of siTrkB(1) and siFGFR1(1). Error bars represent SEM. $p=0.0005$ [siTrkB(1)]; $p<0.0001$ [siFGFR1(1)]; $n=3 . C^{\prime} C^{\prime}$, Two independent siRNAs specific for FGFR1 [siFGFR1(1), siFGFR1(2)] significantly reduced gephyrin dustering in HeLa cells. $n>2730 ; p<0.0001 . D, D^{\prime}$, Two independent siRNAs specificfor TrkB [siTrkB(1), siTrkB(2)] significantly reduced gephyrin clustering in HeLa cells. $n>2640 ; p<0.0001$, ANOVA. Error bars represent SEM. E, In the siRNA screen, intracellular gephyrin deposits can be distinguished from membrane gephyrin by the quantification of gephyrin spot numbers $(n=30)$. $\boldsymbol{F}$, Gephyrin expression is notaltered after siRNA transfection targeting identified hits. Western blot of HeL a cells transfected with siRNA as indicated. G, The lower band refers to endogenous gephyrin also expressed in untransfected HeLa cells (ctr). ${ }^{* *} p<0.0001$. Scale bars, $10 \mu \mathrm{m}$. 


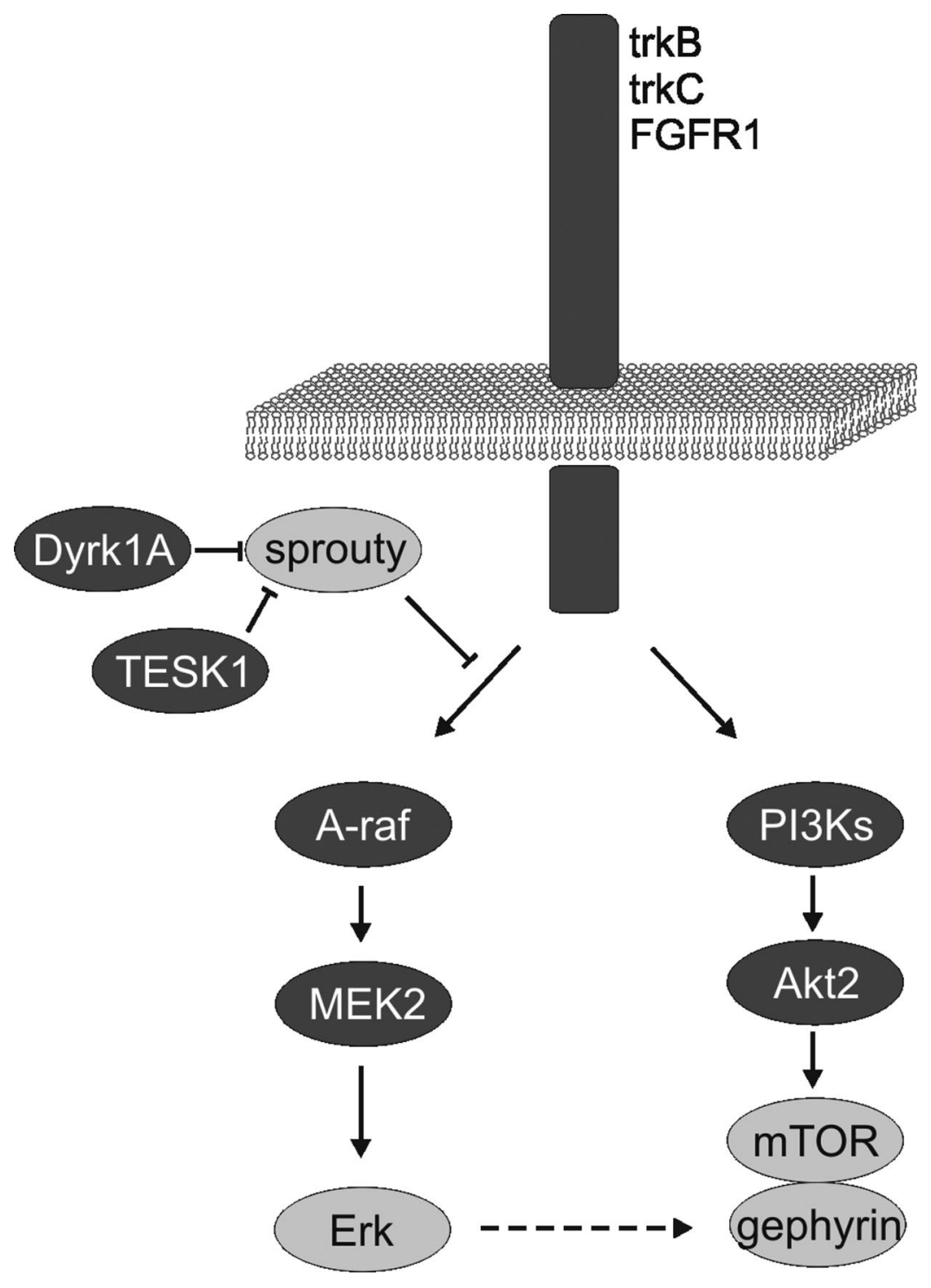

Figure 3. siRNA screening identifies TrkB, TrkC, and FGFR1. Further downstream components cluster in the MAPK and the PI3K-Akt signaling pathway. Hits identified are indicated in dark gray.

both gephyrin and $\mathrm{GABA}_{\mathrm{A}}$ receptor by confocal immunofluorescence microscopy: In the presence of neurofascin and $\mathrm{CBII}_{\mathrm{SH}_{3}-}$, $\mathrm{GABA}_{\mathrm{A}}$ receptors remained completely colocalized with gephyrin (Fig. $1 C-C^{\prime}$ ), indicating that the gephyrin clusters are membrane associated in the presence of neurofascin. The number of gephyrinspecific fluorescent spots observed represents a further criterion for the discrimination between intracellular gephyrin deposits and membrane gephyrin clusters. If gephyrin is located in intracellular deposits, $<10$ fluorescent spots are observed in transfected HeLa cells (Fig. 2E). Membrane-bound gephyrin is expressed in $>100$ spots per cell. Therefore, only cells with $>10$ gephyrin spots were considered in the siRNA screen to focus on reduced clustering rather than impaired transport.

Gephyrin is known to be phosphorylated by protein kinases that may be implicated in the regulation of gephyrin clustering (Langosch et al., 1992; Zita et al., 2007; Huttlin et al., 2010). Therefore, siRNAs targeting the mRNA of all known human protein kinases as well as adapter molecules (710 targets in total, two independent siRNAs for each hit minimum; Fig. 1D) were transfected into HeLa cells for subsequent analysis. Hits were defined as genes for which at least two independent siRNAs were found that reduce EGFP-gephyrin clusters to rule out offtarget effects (for quantification and summary, see Fig. $1 E, F)$. Hits that obviously impaired cell viability were not considered. Hits included siRNAs directed against FGFR1, TrkB, and TrkC, indicating that RTK signaling in general might control gephyrin clustering in HeLa cells. As exemplified for TrkB and FGFR1, knockdown of each receptor by two independent siRNAs resulted in a significant decrease in gephyrin cluster area, while scrambled control siRNA remained ineffective as shown in Figure $2 A-D$. By contrast, the number of gephyrin clusters remained unaffected in HeLa cells (Fig. $2 E)$. Expression and efficient knockdown of TrkB and FGFR1 mRNAs in HeLa cells were analyzed by quantitative RT-PCR (Fig. 2B). Further hits identified represent components of the MAPK pathway including A-raf and MEK2 (Fig. 3). It is noteworthy that, in the case of the MAPK pathway component Erk2, gephyrin clustering was reduced by only one siRNA. Therefore, Erk2 was excluded from the original hit list. Likewise, we identified testicular protein kinase 1 (Tesk1) and dual-specificity tyrosine-phosphorylated and -regulated kinase 1A (Dyrk1A), which represent negative regulators of sprouty2. Sprouty2 antagonizes RTK-induced MAPK signaling (Edwin et al., 2009). In conclusion, independent identification of four regulatory components of MAPK signaling underlines the crucial importance of this pathway for gephyrin clustering in HeLa cells. On the other hand, PI3KAkt signaling components including the three catalytically active kinases PIK3CB, PIK3C3, and PIK3C2G together with Akt2 were identified. Since an interaction of gephyrin with mTOR was previously documented (Sabatini et al., 1999), we supposed that gephyrin clustering may be regulated via mTOR induced by the PI3K-Akt pathway, although the identity of the $\mathrm{PI} 3 \mathrm{~K}$ involved in gephyrin clustering in neurons remains elusive. The siRNAs targeting different hits may also impair the stability of gephyrin rather than clustering. As shown in Figure 2, F and $G$, by Western blot analysis, EGFP-gephyrin fusion protein was expressed together with endogenous gephyrin as a doublet in HeLa cells. Treatment with siRNA specific for TrkB, MEK2, or FGFR1 did not change gephyrin expression, indicating that reduced gephyrin clustering is not caused by decreased gephyrin expression levels.

\section{TrkB signaling regulates gephyrin clustering in neurons}

Having identified candidate protein kinases for the regulation of gephyrin clustering in a HeLa cell-based screen, these were further validated in more relevant primary hippocampal neurons after transfection of additional independent siRNA constructs. Treatment with TrkB-specific siRNA significantly reduced the 


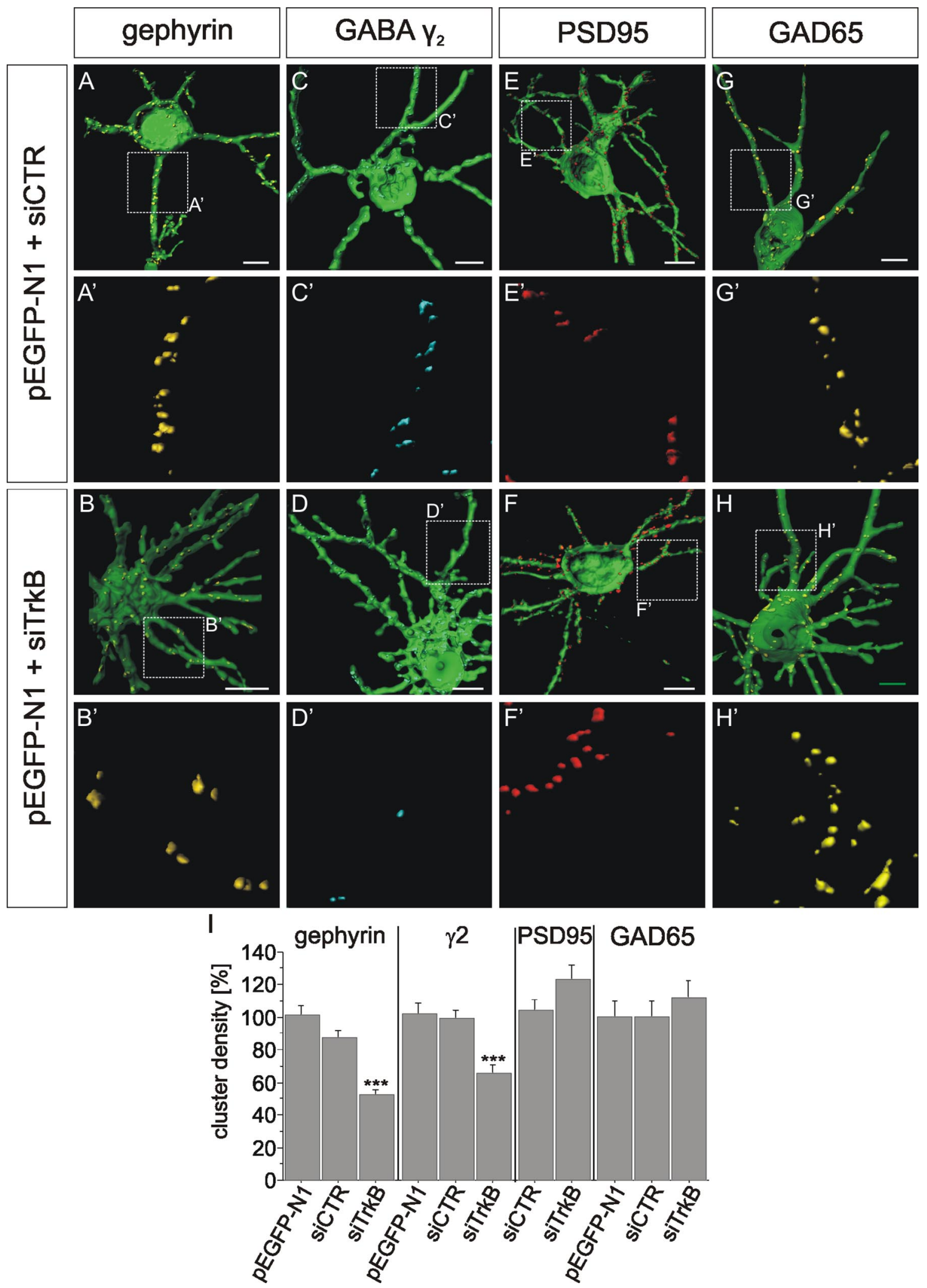

Figure 4. Knockdown of TrkB impairs endogenous gephyrin clustering in hippocampal neurons. pEGFP-N1 was cotransfected with control siRNA or siRNA specific for TrkB. EGFP fluorescence identifies successfully transfected neurons (green; $\boldsymbol{A}-\boldsymbol{H}$ ), while postsynaptic components of dendritic GABAergic synapses are indicated in yellow for gephyrin $\left(\boldsymbol{A}^{\prime}, \boldsymbol{B}^{\prime}\right)$ and blue for the $\gamma 2$ subunit of the $G A B A_{A}$ receptor $\left(\boldsymbol{C}^{\prime}, \boldsymbol{D}^{\prime}\right)$. For control, PSD-95 spots of excitatory synapses are stained in red $\left(\boldsymbol{E}^{\prime}, \boldsymbol{F}^{\prime}\right)$, and GAD65 spots in yellow $\left(\boldsymbol{G}^{\prime}, \boldsymbol{H}^{\prime}\right)$. All images were rendered using Imaris software. $\boldsymbol{I}$, Quantification of gephyrin, $\gamma 2$ subunits of GABA $A_{A}$ receptors, PSD95, and GAD65 cluster densities on dendrites. $n=30$; ${ }^{* *} p<0.0001$, ANOVA. Error bars represent SEM. Scale bars, $10 \mu \mathrm{m}$. 

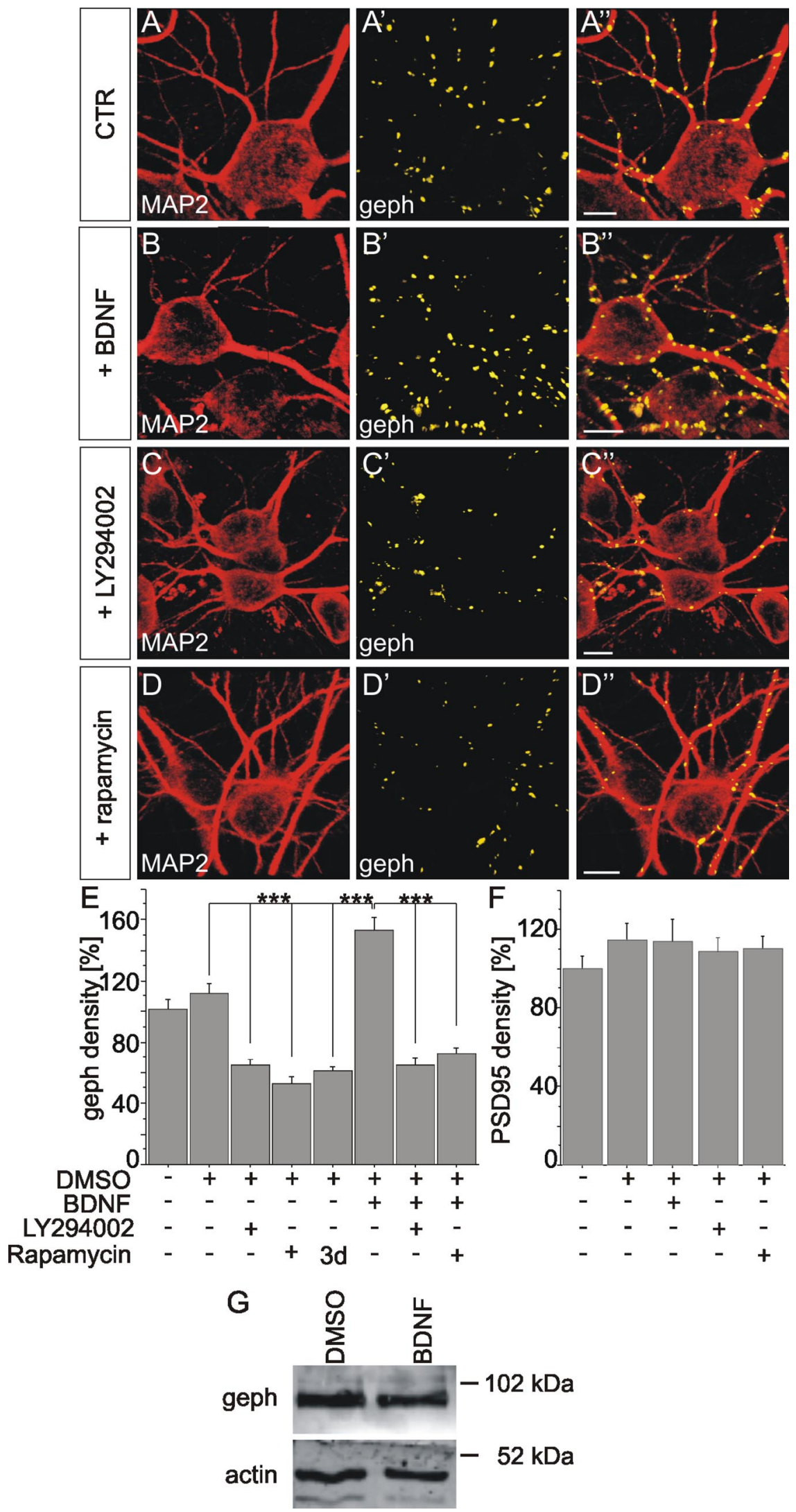

Figure 5. Interference with the PI3K-Akt-mTOR pathway reduces endogenous gephyrin clustering in hippocampal neurons. $\boldsymbol{A}-\boldsymbol{D}$, Representative images of MAP2-stained hippocampal neurons and costaining for gephyrin clusters $\left(\boldsymbol{A}^{\prime}-\boldsymbol{D}^{\prime}\right)$. For merged images, see $\boldsymbol{A}^{\prime \prime}-\boldsymbol{D}^{\prime \prime}$. All images were rendered using Imaris software. Scale bars, $10 \mu \mathrm{m}$. $\boldsymbol{E}$, Quantification of gephyrin cluster densities on MAP2-positive dendrites of hippocampal neurons treated with different inhibitors for $24 \mathrm{~h}$ as indicated. $n=30$ ${ }^{* * *} p<0.0001$. For rapamycin, gephyrin clustering was also observed after $3 \mathrm{~d}$ of incubation ( $3 \mathrm{~d}$ ). $\boldsymbol{F}$, Quantification of PSD-95 expression of TrkB mRNA to $36.6 \%$ of the control level as shown by quantitative RT-PCR $(p<0.0001, t$ test $)$. The density of endogenous gephyrin clusters was quantified on dendritic segments. The TrkB-specific siRNA significantly reduced gephyrin clustering compared with neurons transfected using the control siRNA (Fig. 4). Accordingly, stimulation of hippocampal neurons with BDNF significantly induced gephyrin clustering, which is in line with the previously reported role of $\mathrm{TrkB}$ (Chen et al., 2011) (Fig. 5E). By contrast, clustering of PSD-95, the scaffold molecule of excitatory synapses, remained unaffected. Since gephyrin is involved in the organization of $\mathrm{GABA}_{\mathrm{A}}$ receptors, we inspected clustering of the $\gamma 2$ subunit, which is required for postsynaptic clustering of $\mathrm{GABA}_{\mathrm{A}}$ receptors (Essrich et al., 1998). In addition to affecting gephyrin clustering, TrkB knockdown also impaired clustering of the $\gamma 2$ subunit of $\mathrm{GABA}_{\mathrm{A}}$ receptors. A possible contribution of presynaptic mechanisms was tested by quantification of GAD65-positive spots on dendrites. However, no significant change in the density of GAD65 spots was observed. This is in accordance with our screening system, which detects hits in the absence of presynaptic input. In conclusion, our results confirm the results of the HeLa cell-based screen and link BDNF-TrkB signaling to gephyrin and concomitant $\mathrm{GABA}_{\mathrm{A}}$ receptor clustering.

Involvement of Akt-mTOR and MAPK pathways in gephyrin clustering

To further corroborate the function of BDNF-TrkB signaling, we analyzed a possible contribution of the PI3K-AktmTOR pathway for gephyrin clustering in cultured hippocampal neurons. As shown in Figure 5, the mTOR antagonist rapamycin efficiently reduced the density of endogenous gephyrin clusters on dendrites. A possible explanation for this effect may rely on the action of endogenous BDNF secreted in functionally active cultures. mTOR may be activated by BDNFTrkB signaling via PI3K and Akt, both of which were hits in the primary screen in HeLa cells. Accordingly, inhibition of PI3K by LY94002 significantly reduced the density of gephyrin clusters. Increased

cluster densities on MAP2-positive dendrites of hippocampal neurons using different inhibitors as indicated. $n=40$; ANOVA. Error bars represent the SEM. G, BDNF does not increase gephyrin expression levels in primary neurons. Shown is a Western blot of gephyrin expressed in control neurons (DMSO) or neurons stimulated stimulated with BDNF; actin signals served as a loading control. 

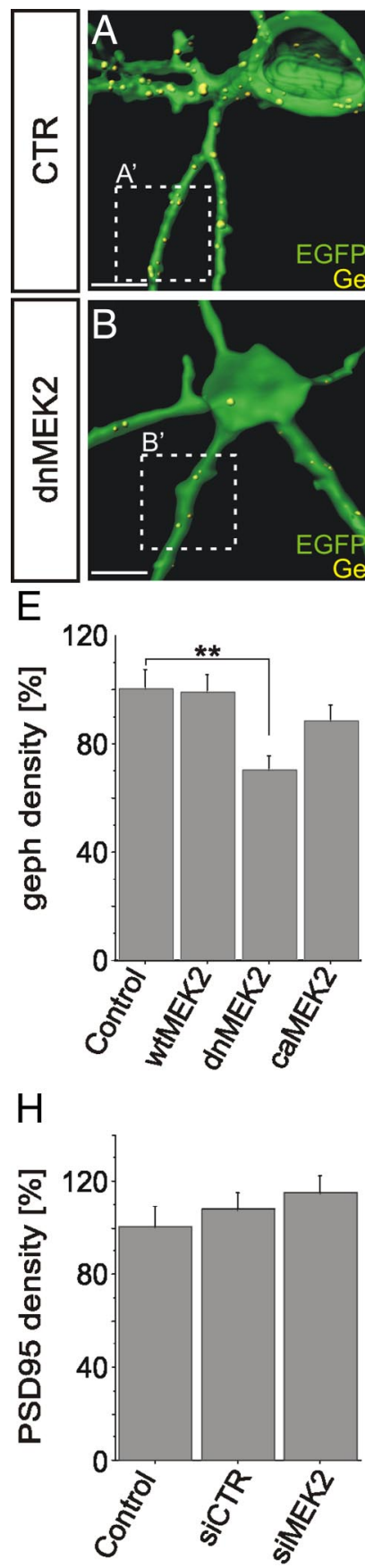
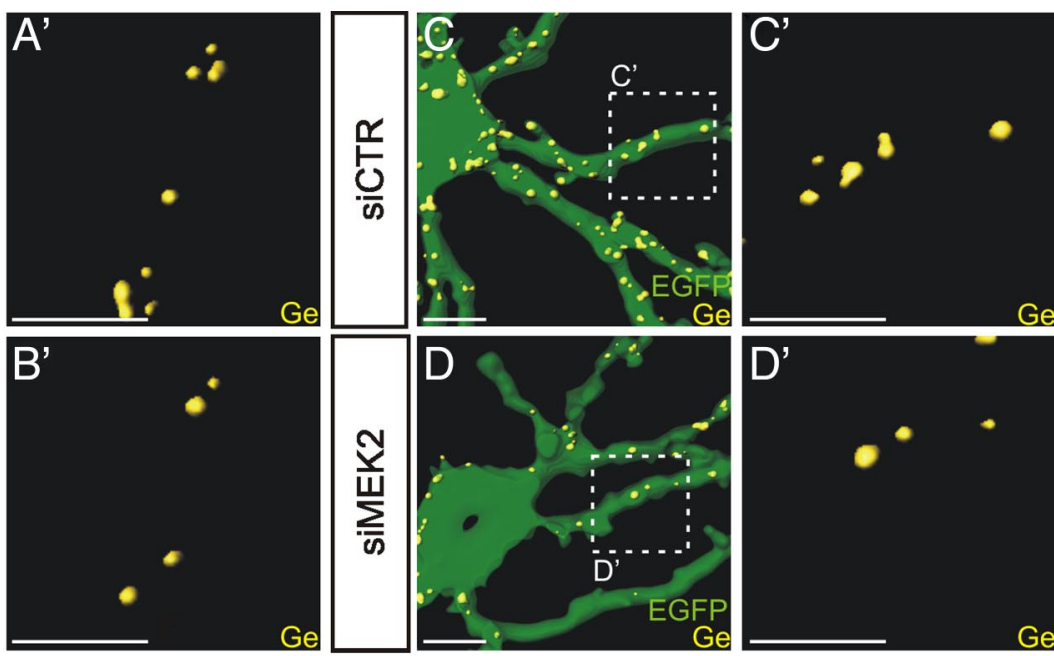

F

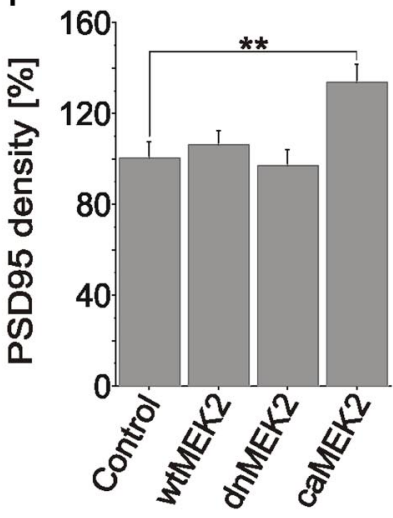

I

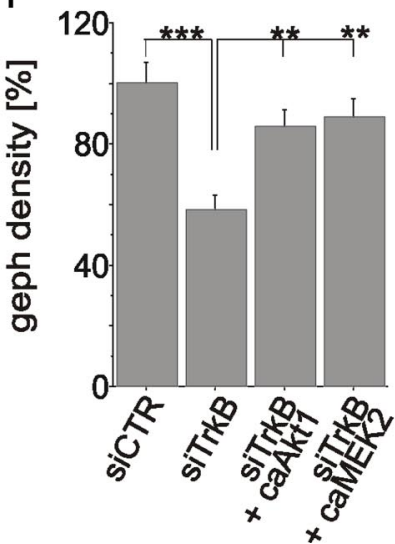

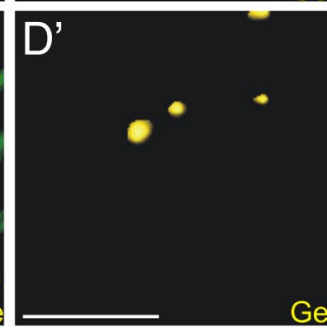

G
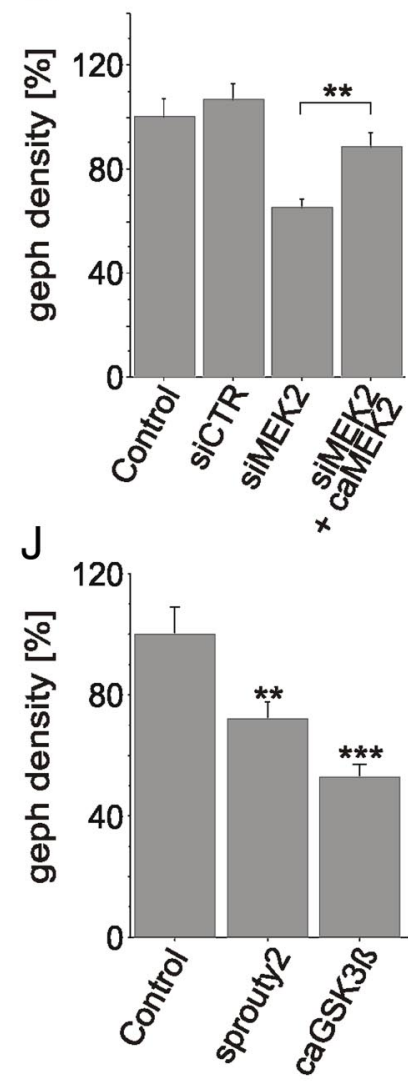

Figure 6. Interference with the MAPK pathway reduces endogenous gephyrin cluster density in hippocampal neurons. pEGFP-N1 was transfected together with further constructs as indicated. $\boldsymbol{A}-\boldsymbol{D}$, Hippocampal neurons were mock-transfected $\left(\boldsymbol{A}, \boldsymbol{A}^{\prime}, \mathrm{CTR}\right)$ or transfected with dominant-negative MEK2 ( $\boldsymbol{B}, \boldsymbol{B}^{\prime}$, , dnMEK2), control siRNA (C, $\boldsymbol{C}^{\prime}$, siCTR), or siRNA specific for MEK2 ( $\boldsymbol{D}, \boldsymbol{D}^{\prime}$, siMEK2). EGFP fluorescence identifies successfully transfected neurons (green; $\boldsymbol{A}-\boldsymbol{D})$, while postsynaptic components of dendritic GABAergic synapses are indicated in yellow. Gephyrin-positive spots are enlarged in $\boldsymbol{A}^{\prime}-\boldsymbol{D}^{\prime}$. All images were rendered using Imaris software. Scale bars, $10 \mu \mathrm{m}$. $\boldsymbol{E}$, Quantification of the gephyrin cluster density after overexpression of different MEK2 overexpression constructs. $n=60 ; p=0.0016$.F, Quantification of PSD-95 cluster densities after overexpression of different MEK2 overexpression constructs. $n=60 ; p=0.0020$. G, Quantification of the gephyrin cluster density after transfection of siRNA specific for MEK2 and rescue by caMEK2 overexpression. $n=60 ; p<0.0001 ; p=0.0062$. $\boldsymbol{H}$, Quantification of PSD-95 cluster density after transfection of MEK2-specific siRNA. $n=60$. I, Quantification of gephyrin cluster density after cotransfection of trkB-specific siRNA and constitutively active MEK2 or Akt1 for rescue. $n=30 ; p<0.0001$ (siCTR vs siTrkB); $p=0.0009$ (siTrkB vs siTrkB/caAkt1); $p=0.0002$ (siTrkB vs siTrkB/caMEK2). J, Quantification of the gephyrin cluster density after cotransfection of overexpression constructs for sprouty2 or constitutively active GSK3 $\beta$. sprouty2, $n=40, p<0.0086, n=30$, GSK3 $\beta, p<0.0001$, ANOVA. Error bars represent SEM. ${ }^{* *} p<0.01 ;{ }^{* * *} p<0.0001$.

gephyrin clustering in the presence of exogenous BDNF was also sensitive to rapamycin or LY294002 treatment. On the other hand, PSD-95 clustering remained unchanged in the presence of mTOR or PI3K inhibitors, suggesting that the viability and general functionality of neurons is not compromised by inhibitor treatments. Western blot analysis revealed that BDNF treatment did not affect endoge- nous gephyrin expression (Fig. 5G), indicating that BDNF modulated gephyrin clustering rather than gephyrin expression.

Gephyrin clustering was further inspected in hippocampal neurons after transfection of siRNA specific for MEK2 as well as constitutively active or dominant-negative variants of MEK2 (caMEK2 and dnMEK2, respectively) (Fig. 6A-I). Overexpression 
A ERK1/2 pT202/Y/204

Akt pSer473

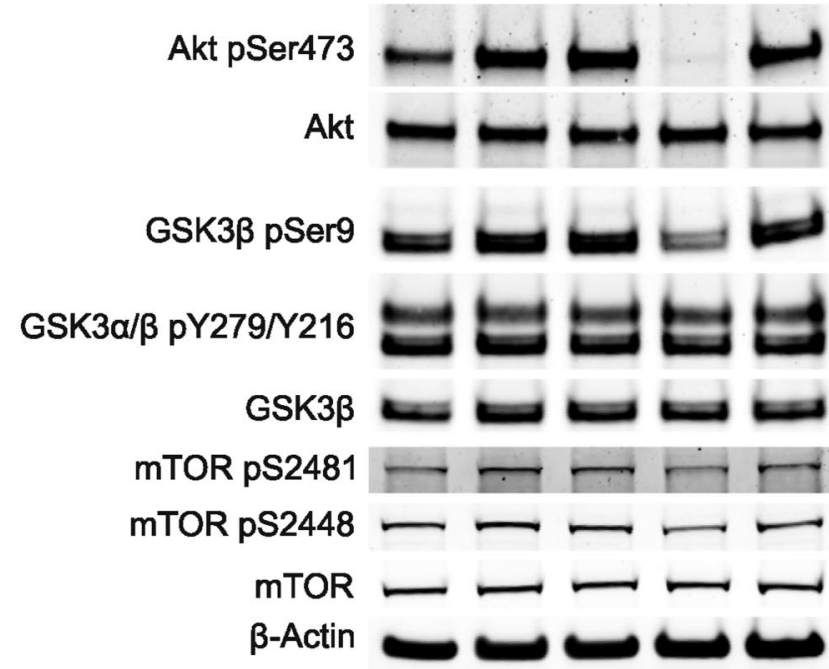

B

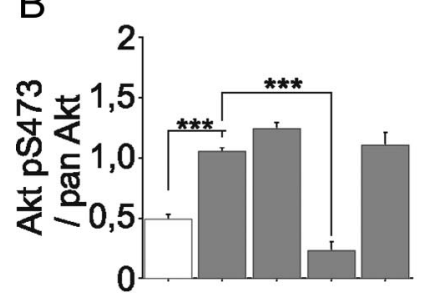

C

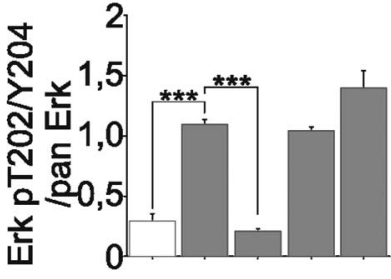

D

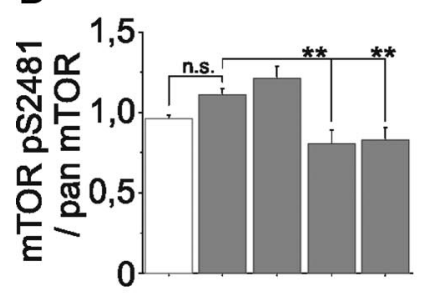

E

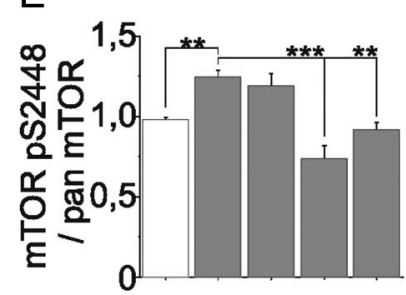

F

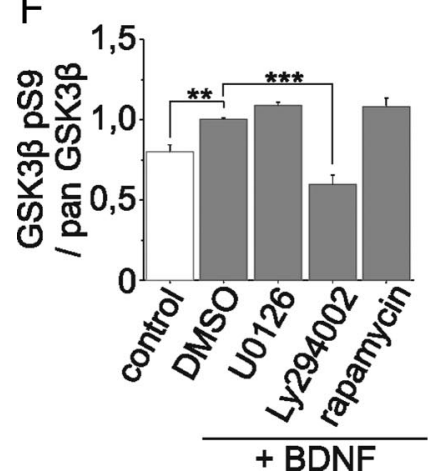

$\mathrm{G}$

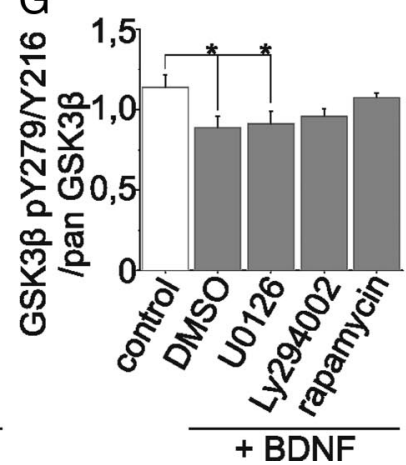

Figure 7. Characterization of BDNF-dependent signaling pathways. $\boldsymbol{A}$, Western blot analysis of TrkB downstream signaling pathways of untreated neurons, BDNF-stimulated neurons, as well as neurons preincubated with inhibitors U0126, LY294002, and rapamycin, respectively. Erk1/2 pT202/Y204, pan ERK1/2, Akt pS473, panAkt, GSK3 $\beta$ pSer9, GSK3 pY279/Y216, panGSK3 $\beta$, mTOR

of dnMEK2 significantly reduced the density of gephyrin clusters, while overexpression of caMEK2 did not affect gephyrin clustering (Fig. 6E). Possibly, the amount of available gephyrin molecules for clustering was limiting. By contrast, overexpression of dnMEK2 did not affect PSD-95 (Fig. 6F), while caMEK2 induced PSD-95 clustering. siRNA targeting MEK2 reduced the density of endogenous gephyrin clusters significantly (Fig. 6G). Generally, retraction of synapses may be induced by siRNA-induced off-target effects and therefore require further controls (Alvarez et al., 2006). The observed reduction of gephyrin clustering by MEK2-specific siRNA was partially restored by coexpression of human caMEK2 not targeted by rat siRNA indicating that off-target effects are not involved (Fig. 6G). In a further control experiment, clustering of PSD-95positive spots remained unaffected by siRNA specific for MEK2 (Fig. 6H). Reduced gephyrin cluster density after trkB knockdown was also rescued in the presence of overexpressed caAkt1 or caMEK2. Therefore, BDNF-TrkB induced gephyrin clustering may rely on independent activity of either the MAPK or the PI3KAkt pathway (Fig. 6I). The identification of Tesk1 and Dyrk1A as essential modulators of gephyrin clustering in the HeLa cell screen led us to ask for a role of the MAPK pathway antagonist sprouty2, which is expressed in neurons and may serve as a target for Tesk1 and Dyrk1A (Hausott et al., 2012). Transfection of an expression vector for sprouty2 significantly reduced gephyrin clustering, indicating that Tesk1- and Dyrk1Adependent inhibition of sprouty 2 may be required for gephyrin clustering (Fig. 6J). GSK3 $\beta$ was previously shown to negatively regulate gephyrin clustering (Tyagarajan et al., 2011a). Accordingly, overexpression of caGSK3 $\beta$ lacking Ser9 reduced gephyrin clustering (Fig. 6J).

$\leftarrow$

pS2481, mTOR pS2248, and pan mTOR signals are depicted as indicated. $\boldsymbol{B}-\mathbf{G}$, Densitometric quantification of Western blot bands. Bar charts represent signal ratios of phosphorylated moieties versus total protein (pan). $\boldsymbol{B}$, Quantification of Akt pS473/panAkt. $n=4 ;{ }^{* * *} p<0.0001$. C, Quantification of Erk1/2 pT202/Y204/panErk1/2. $n=4 ;{ }^{* * *} p<0.0001$. D, Quantification of $\mathrm{mTOR}$ pS2481/pan mTOR. $n=4, p=0.0048$ (for BDNF vs BDNF/LY294002), and $p=0.0072$ (for BDNF vs BDNF/rapamycin); n.s., not significant. $E$, Quantification of mTOR pS2248/pan mTOR. $n=4, p=0.0091$ (for control vs BDNF), $p<0.0001$ (for BDNF vs BDNF/LY294002), and $p=$ 0.0021 (for BDNF vs BDNF/rapamycin). $\boldsymbol{F}$, Quantification of GSK3 $\beta$ pS9/panGSK3 $\beta . n=4 ;{ }^{* *} p=0.0038 ;{ }^{* * *} p<$ 0.0001. G, Quantification of GSK3 $\beta$ pY279/pY216/panGSK3 $\beta$. $p=0.0254$ (for control vs BDNF), $p=0.0399$ (for control vs BDNF/U0126); $n=4$; ANOVA. Error bars represent SEM. 
In conclusion, application of MEK2specific siRNA and dnMEK2 as well as overexpression of sprouty2 clearly indicated that the MAPK pathway is involved in gephyrin clustering in primary neurons, too.

\section{Activation of MAPK and mTOR signaling in primary neurons}

Our results imply an involvement of both MAPK and PI3K pathways in the BDNFdependent regulation of gephyrin clustering. For further confirmation, we analyzed the activation state of specific signaling components of both pathways in primary neurons (Fig. 7). As expected, BDNF induced phosphorylation of ERK1/2 and Akt in primary neurons. ERK1/2 phosphorylation was inhibited by MEK inhibitor U0126, while Akt phosphorylation was inhibited by PI3K inhibitor (LY294002; Fig. 7 B, C), suggesting activation of canonical MAPK and PI3K pathways by BDNF (Reichardt, 2006).

Inspection of mTOR phosphorylation revealed that BDNF treatment induced serine 2448 phosphorylation significantly, while no significant effects were observed on serine 2481 (Fig. 7 D,E). Serine 2481 is a target of mTOR autocatalytic, rapamycinsensitive activity and may reflect the activation status of mTOR (Soliman et al., 2010). mTOR phosphorylation by Akt or by the mTOR downstream effector S6K1 at serine 2448 accounts for the feedback regulation of mTOR activity (Holz and Blenis, 2005). Phosphorylation of both sites was significantly blocked by either PI3K inhibitor LY294002 or mTOR antagonist rapamycin. We did not observe an impact of MEK inhibitor U0126, suggesting that mTOR activity was not regulated by a cross talk of the MAPK pathway upstream of mTOR. Thus, BDNF might activate mTOR via the canonical PI3KAkt pathway.

BDNF stimulation did not induce tyrosine 279/216 phosphorylation of GSK3 $\beta$; however, serine 9 phosphorylation was significantly upregulated (Fig. $7 F, G$ ). Serine 9 phosphorylation was sensitive to PI3K inhibitor LY294002, while MEK inhibitor U0126 and mTOR antagonist rapamycin were ineffective. Therefore, BDNF treatment induces GSK3 $\beta$ phosphorylation at serine 9 via PI3K. Since this site negatively regulates the activity of GSK $3 \beta$, our data are in accordance with the previous findings that GSK3 $\beta$ is a negative regulator of gephyrin clustering (Tyagarajan et al., 2011a). Accordingly, GSK3 $\beta$ deleted in Ser9 inhibits gephyrin clustering (Fig. 6J).

In summary, $\mathrm{BDNF} / \mathrm{TrkB}$-induced gephyrin clustering is accompanied by the activation of the MAPK and the PI3K-Akt pathway. PI3K-Akt signaling activates mTOR, while GSK3 $\beta$ becomes inactivated. MAPK signaling appeared not to modulate mTOR via cross talk to Tsc1/2 (Tee et al., 2003; Ma et al., 2005; Ehninger et al., 2009).
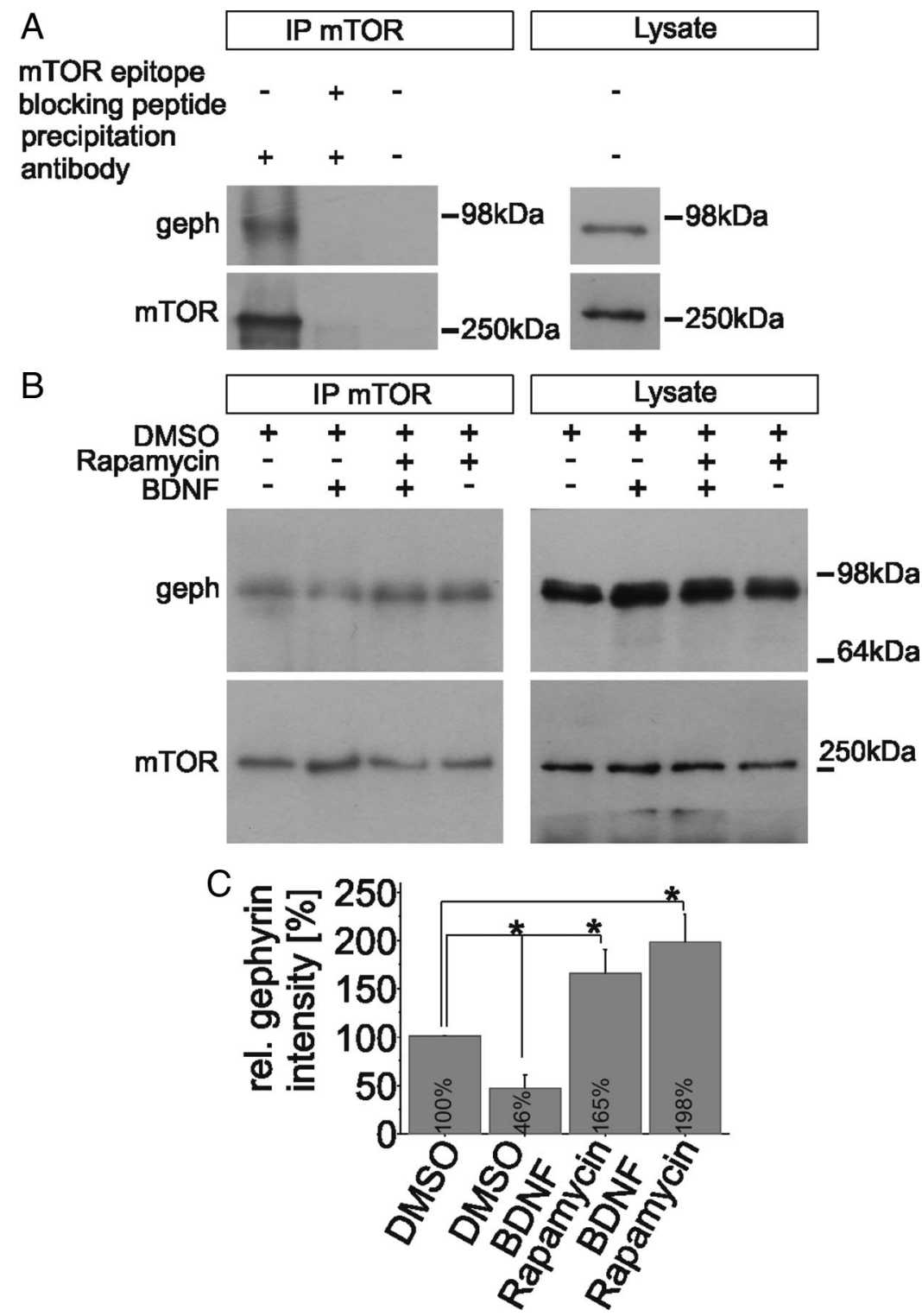

Figure 8. Gephyrin and mTOR interaction after treatment with BDNF or mTOR inhibitor rapamycin. $A$, Coimmunoprecipitation of gephyrin and mTOR using an antibody against mTOR for precipitation either preincubated or not preincubated with a blocking rin and mTOR were detected by specific antibodies in lysates and precipitates as indicated. Cultured neurons were pretreated with amount of immunoprecipitated gephyrin after treatments as indicated in $\boldsymbol{B}$. Band intensities are given as ratios of gephyrin/mTOR normalized to DMSO control, $n=3,{ }^{*} p<0.05$ relative to DMSO, ANOVA. Error bars represent SEM.

\section{Activated mTOR dissociates from gephyrin}

To elucidate a possible role of mTOR for gephyrin clustering more precisely, we performed coprecipitation experiments. We asked whether endogenous mTOR associates with gephyrin in neurons and whether the activation of mTOR modulates the interaction with gephyrin. Our results show that endogenous $\mathrm{mTOR}$ and gephyrin coprecipitated from lysates prepared from dissociated cortical neurons (Fig. 8A). BDNF stimulation significantly decreased gephyrin-mTOR coprecipitation, indicating that direct or indirect interactions between gephyrin and mTOR were weakened upon mTOR stimulation (Fig. 8B,C). Accordingly, application of the mTOR inhibitor rapamycin increased gephyrin-mTOR interactions dramatically, indicating that inactive mTOR efficiently complexes with gephyrin. Rapamycin 

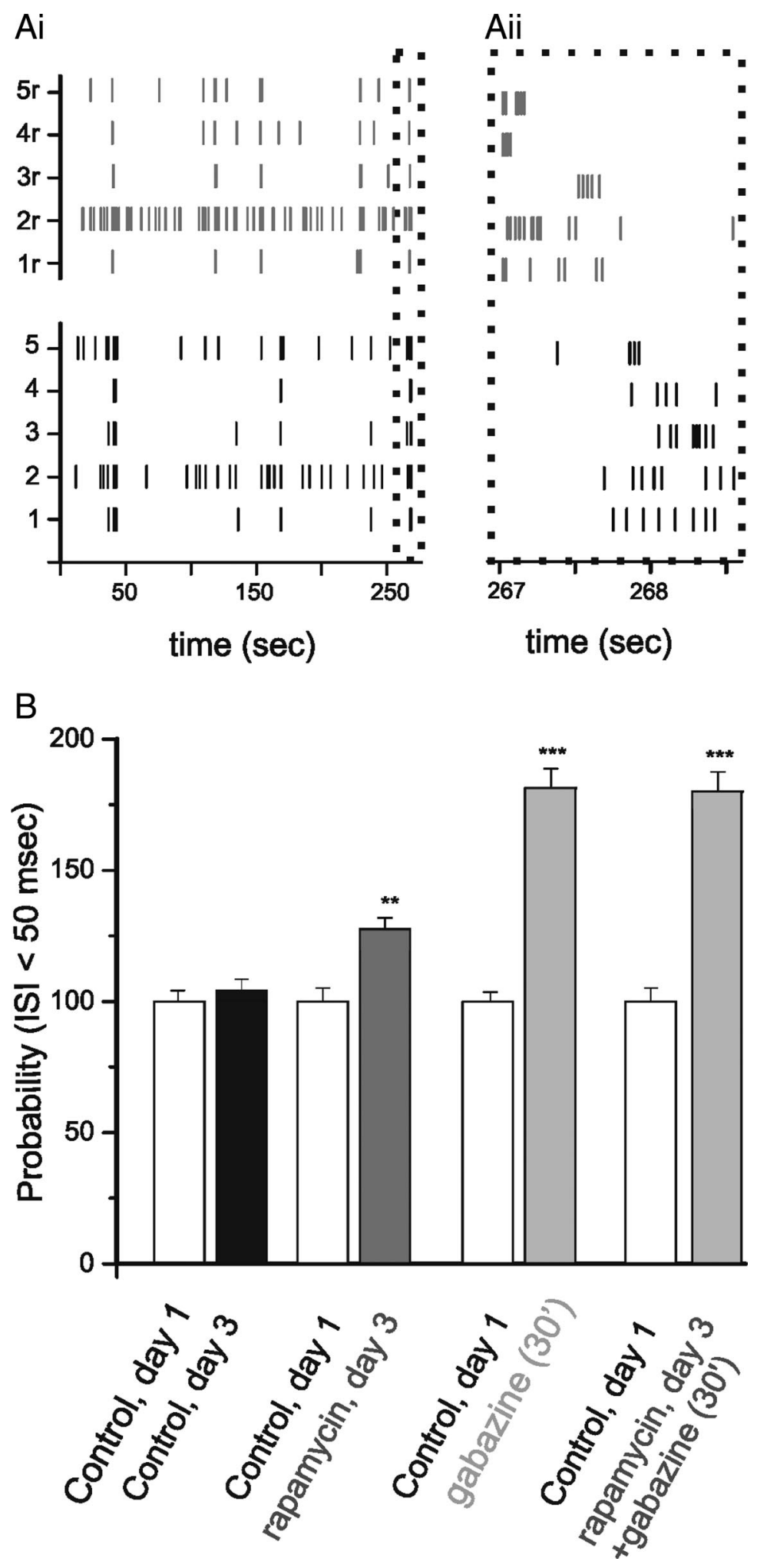

Figure 9. Physiological differences in neuronal cultures after treatment with mTOR inhibitor rapamycin and $\mathrm{GABA}_{A}$ receptor blocker gabazine (SR 95531). Ai, Spike patterns of five neurons before the application of rapamycin (rows 1-5) and $3 \mathrm{~d}$ after the application (rows 1r-5r) recorded on the same microelectrode array. Each tick marks the occurrence of a neuronal spike or a short sequence thereof. The dotted rectangle around recording time 250 s is enlarged in Aii. The interspike intervals of individual neurons appear shorter after the application of rapamycin. $\boldsymbol{B}$, Probability to detect interspike intervals $<50 \mathrm{~ms}$ in the spike trains of the neuron changes significantly for the treated cultures but not for the control cultures. The average probability to measure intervals $<50 \mathrm{~ms}$ (DIV 21) differs for the four treatments. The average probability increased significantly in cultures treated with rapamycin $\left({ }^{* *} p<0.01\right)$, gabazine $\left.{ }^{* * *} p<0.001\right)$, and rapamycin together with gabazine $\left.{ }^{* * *} p<0.001\right)$. There was no change in control cultures (DIV 24). Error bars represent SEM. treatment also increased gephyrin-mTOR association in the absence of exogenous BDNF. In conclusion, these results imply that inactive mTOR interacts with gephyrin. Activated mTOR dissociates from gephyrin and may thereby release gephyrin for submembrane association and clustering.

mTOR inhibition resembles the pharmacological blockade of inhibitory receptors

Our results suggest a crucial contribution of mTOR activation for gephyrin clustering, which may also regulate the clustering of $\mathrm{GABA}_{\mathrm{A}}$ receptors. If this holds true, interference with mTOR signaling should disturb inhibitory synapse functions. To test this hypothesis, dissociated cortical neurons were cultivated on microelectrode arrays for $21 \mathrm{~d}$ when stable neuronal networks have been established. Network properties were analyzed in control cultures, in cultures treated with rapamycin, and in cultures treated with the $\mathrm{GABA}_{\mathrm{A}}$ receptor blocker gabazine (SR 95531). Stable networks were defined based upon the bursting behavior in which a large percentage of cells engaged in simultaneous population activity (Chiappalone et al., 2006; Mazzoni et al., 2007). As shown in Figure $9 A$, cells in such networks exhibited spontaneous activity with a high percentage of spikes ( $36 \% ; n=539$ cells) occurring within $<50 \mathrm{~ms}$. To assess the effect of rapamycin, eight cultures were treated for $3 \mathrm{~d}$ with rapamycin $(1 \mu \mathrm{M})$ and three cultures were treated with gabazine $(20 \mu \mathrm{M}, 30 \mathrm{~min})$ and five more cultures served as controls and were not treated at all. The probability to measure interspike intervals $<50$ ms was calculated and averaged over all identified cells. There was a significant increase in short intervals for rapamycin-treated neurons (24\% increase; $n=235$ neurons) as shown in Figure $9 B$. The increase was larger for the gabazinetreated neurons ( $80 \%$ increase; $n=148$ ) but did not occur in the control cultures ( $4 \%$ increase; $n=205$ ). It is unlikely that excitatory functions in the neuronal cultures had changed and thus decreased gephyrin or GABA clusters by homeostatic compensation (Rannals and Kapur, 2011) for the following reasons: (1) the mean firing rate and the number of firing neurons in rapamycin-treated cultures estimated at three postapplication time points (see Materials and Methods) did not change significantly, which also excludes an effect on neuronal viability; (2) upon inhibition of excitatory NMDA receptors the probability for long interspike 
intervals should increase (Mazzoni et al., 2007) — opposite to our observation. To further rule out changes in neuronal excitability, we added the blocker gabazine to three cultures that were treated for $3 \mathrm{~d}$ with rapamycin. Combination of rapamycin and gabazine did not further enhance the effect of gabazine (79\% increase; $n=$ 25; Fig. 9B). Thus, our results confirm a contribution of mTOR signaling to the stabilization of gephyrin clusters and GABAergic synapses at the functional level.

\section{Discussion}

A kinome-wide siRNA screen was used to identify protein kinases implicated in gephyrin clustering. Identification of FGFR1, TrkB, and $\mathrm{TrkC}$ and downstream signaling components of the MAPK and PI3K-Akt-mTOR emphasized the pivotal role of RTK signaling. While BDNF activated mTOR signaling, GSK3 $\beta$ became inactivated, suggesting a dual role of TrkB signaling. Coprecipitation assays indicated that the mTOR-gephyrin association was dissolved upon mTOR activation. Electrophysiological recordings indicate a requirement of mTOR signaling for GABAergic functions.

The identification of the RTKs FGFR1 and TrkB is in accordance with previous findings that demonstrated an involvement of TrkB in the control of gephyrin clusters in cerebellar neurons (Chen et al., 2011) and of neurofascin-FGFR1 signaling for gephyrin clustering and synaptic stabilization at the axon initial segment of granular neurons of the hippocampus (Kriebel et al., 2011). Hence, different RTKs either controlled by ligand interactions as in the case of BDNF or by coreceptors (e.g., neurofascinFGFR1 interactions) account for the control of gephyrin clustering independently of each other. BDNF-TrkB signaling was previously shown to regulate synaptogenesis of inhibitory synapses (Seil and Drake-Baumann, 2000). Furthermore, BDNF induces a dynamic, time-dependent change in mIPSCs thought to be mediated by transient association of PKC with the $\beta 3$ subunit of $\mathrm{GABA}_{\mathrm{A}}$ receptors and subsequent endocytosis (Brünig et al., 2001; Jovanovic et al., 2004). Therefore, stabilization of both $\mathrm{GABA}_{\mathrm{A}}$ receptors and gephyrin is regulated by BDNF. In the case of excitatory synapses, BDNF-TrkB signaling was shown to modulate postsynaptic functions of glutamatergic synapses by different mechanisms. Spine dynamics and LTP, cytoskeletal rearrangements, and translational control are regulated by BDNF (Bramham, 2008). Likewise, BDNF facilitates synaptic $\mathrm{Ca}^{2+}$ entry through voltage-gated channels or NMDA receptors and increases the expression and trafficking of AMPA receptors (Minichiello, 2009). Therefore, BDNF-TrkB signaling developed as a mechanism regulating synapse formation, stabilization, and function in general.

There are three main signaling pathways triggered after activation of TrkB, including the MAPK, the PI3K-Akt, and the PLC $\gamma$ pathways (Yoshii and Constantine-Paton, 2010). Our results provide a novel link between BDNF, MAPK, and PI3K-Akt signaling in the context of gephyrin clustering. The PI3K-Akt pathway controls mTOR via regulation of the Tsc1/2 complex and of the mTOR inhibitor Rheb (Manning et al., 2002; Wullschleger et al., 2006). Here, we show that BDNF induces gephyrin clustering via mTOR activation. In parallel, BDNFdependent activation of mTOR decreases the association between mTOR and gephyrin. Therefore, gephyrin clustering might require release of the mTOR-gephyrin complex to allow for gephyrin membrane translocation for the formation of postsynaptic scaffolds. By contrast, the authors of a previous report failed to identify an impact of rapamycin on gephyrin-mTOR interactions (Sabatini et al., 1999). This discrepancy may be explained by the use of in vitro binding assay in the previous report, which reflected mechanisms of endogenous proteins only poorly. In addition to the activation of mTOR, PI3K may also be implicated in gephyrin clustering via the regulation of collybistin-phosphatidyl-3-phosphate interactions (Kalscheuer et al., 2009).

Gephyrin phosphorylation may be a crucial mechanism to regulate clustering. A proteomic screen revealed phosphorylation sites at serines 188, 194, and 200 (Huttlin et al., 2010; Luscher et al., 2011). Additionally, gephyrin becomes phosphorylated at serine 270 by GSK $3 \beta$ resulting in decreased gephyrin cluster formation (Tyagarajan et al., 2011a). Our results show that the BDNF-stimulated increase in gephyrin clustering is accompanied by increased phosphorylation of GSK3 $\beta$ at serine 9, which is implicated in GSK3 $\beta$ inhibition (Sugden et al., 2008). Therefore, BDNF acts at two different levels to increase gephyrin clustering. While BDNF positively controls gephyrin clustering via mTOR signaling, antagonistic gephyrin phosphorylation by GSK3 $\beta$ becomes downregulated. Serine 9 phosphorylation may be accomplished by Wnt signaling, Akt, ILK, PKA, and Rsk, the latter of which is downstream of the MAPK pathway (for review, see Medina and Wandosell, 2011). Our results show that serine 9 phosphorylation was decreased in the presence of the PI3K inhibitor LY294002, but not by the MEK inhibitor U0126. Therefore, our results indicate that BDNF-dependent GSK3 $\beta$ inhibition presumably relies on the PI3K-Akt pathway. Possible additional upstream regulators of GSK3 $\beta$ phosphorylation may reside in the canonical Wnt signaling pathway. However, an impact of Wnt stimulation on $\mathrm{GABA}_{\mathrm{A}}$ receptor or gephyrin clustering has not been observed so far (Cuitino et al., 2010).

BDNF stimulation led to Erk phosphorylation in parallel with the induction of gephyrin clustering, indicating a contribution of the MAPK pathway in parallel with the PI3K-Akt-mTOR pathway. Activity of both MAPK and PI3K-Akt pathways was also found to account for dendritic morphogenesis (Kumar et al., 2005). It remained unclear whether these pathways act independently of each other or whether they converge on mTOR. In principle, the MAPK pathway may couple into the mTOR pathway via Erk or Rsk phosphorylation of the Tsc1/2 complex (Tee et al., 2003; Ma et al., 2005; Ehninger et al., 2009). However, mTOR phosphorylation remained insensitive to MEK inhibitor U0126, suggesting an alternative mechanism.

MAPK signaling may be controlled by sprouty proteins. Accordingly, Tesk1 and Dyrk1A, which represent protein kinases implicated in the phosphorylation and inhibition of sprouty protein(s), were identified in the siRNA screen. Four different sprouty genes were found in the human genome termed sproutyl-4 (Edwin et al., 2009), all of which interact with DYRK1A (Aranda et al., 2008). Out of the sprouty proteins, sprouty 2 is expressed in neuronal dendrites and serves for the negative control of BDNF and FGFR1 signaling required for neuronal differentiation and survival (Gross et al., 2007; Aranda et al., 2008). Likewise, our results suggest a further function of sprouty2 for gephyrin clustering. In the case of FGFR1 signaling, DYRK1A inhibits sprouty2 via phosphorylation of Thr75. Accordingly, exchange of Thr75 for Ala leads to a decreased FGFRdependent Erk1/2 activation (Aranda et al., 2008). Here, we showed that DYRK1A expression is also required for gephyrin clustering. The second sprouty 2 interaction partner identified in the siRNA screen was Tesk1, which releases the inhibitory function of sprouty 2 on ERK1/2 phosphorylation by preventing the interaction of sprouty with the RTK adaptor protein Grb2 (Chandramouli et al., 2008). Therefore, the impact of both Tesk1, 
Dyrk1A, and their target sprouty 2 supports the assumption that MAPK signaling is important for gephyrin clustering.

Our results document a comprehensive overview of protein kinases involved in gephyrin clustering. Interestingly, the hits identified correlate with CNS disorders. BDNF and FGFR1 signaling are discussed in the context of stress disorders and depression (Larsen et al., 2010). Inhibition of GSK3 $\beta$ by lithium provides a therapy for mood disorders (Young, 2009). MEK mutations correlate with cognitive deficits (Dentici et al., 2009). TSC1/2 mutations and mTOR signaling may be involved in autism and cognitive deficits (Ehninger et al., 2009; Ehninger and Silva, 2011). Our findings open a new view on signaling pathways relevant for CNS disorders. For a more elaborate picture, it is mandatory to expand the siRNA screen to further protein families to identify novel components implicated in gephyrin clustering. Together, our approach may offer a possibility to analyze signatures of activated signaling pathways in the context of inhibitory synapse stabilization with the aim to understand and classify CNS diseases on a functional basis.

\section{References}

Alvarez VA, Ridenour DA, Sabatini BL (2006) Retraction of synapses and dendritic spines induced by off-target effects of RNA interference. J Neurosci 26:7820-7825. CrossRef Medline

Aranda S, Alvarez M, Turró S, Laguna A, de la Luna S (2008) Sprouty2mediated inhibition of fibroblast growth factor signaling is modulated by the protein kinase DYRK1A. Mol Cell Biol 28:5899-5911. CrossRef Medline

Bao S, Chen L, Qiao X, Thompson RF (1999) Transgenic brain-derived neurotrophic factor modulates a developing cerebellar inhibitory synapse. Learn Mem 6:276-283. CrossRef Medline

Bramham CR (2008) Local protein synthesis, actin dynamics, and LTP consolidation. Curr Opin Neurobiol 18:524-531. CrossRef Medline

Brünig I, Penschuck S, Berninger B, Benson J, Fritschy JM (2001) BDNF reduces miniature inhibitory postsynaptic currents by rapid downregulation of $\mathrm{GABA}_{\mathrm{A}}$ receptor surface expression. Eur J Neurosci 13:1320-1328. CrossRef Medline

Chandramouli S, Yu CY, Yusoff P, Lao DH, Leong HF, Mizuno K, Guy GR (2008) Tesk1 interacts with Spry2 to abrogate its inhibition of ERK phosphorylation downstream of receptor tyrosine kinase signaling. J Biol Chem 283:1679-1691. CrossRef Medline

Chen AI, Nguyen CN, Copenhagen DR, Badurek S, Minichiello L, Ranscht B, Reichardt LF (2011) TrkB (tropomyosin-related kinase B) controls the assembly and maintenance of GABAergic synapses in the cerebellar cortex. J Neurosci 31:2769-2780. CrossRef Medline

Chiappalone M, Bove M, Vato A, Tedesco M, Martinoia S (2006) Dissociated cortical networks show spontaneously correlated activity patterns during in vitro development. Brain Res 1093:41-53. CrossRef Medline

Cuitino L, Godoy JA, Farías GG, Couve A, Bonansco C, Fuenzalida M, Inestrosa NC (2010) Wnt-5a modulates recycling of functional $\mathrm{GABA}_{\mathrm{A}}$ receptors on hippocampal neurons. J Neurosci 30:8411-8420. CrossRef Medline

Dentici ML, Sarkozy A, Pantaleoni F, Carta C, Lepri F, Ferese R, Cordeddu V, Martinelli S, Briuglia S, Digilio MC, Zampino G, Tartaglia M, Dallapiccola B (2009) Spectrum of MEK1 and MEK2 gene mutations in cardiofacio-cutaneous syndrome and genotype-phenotype correlations. Eur J Hum Genet 17:733-740. CrossRef Medline

Edwin F, Anderson K, Ying C, Patel TB (2009) Intermolecular interactions of Sprouty proteins and their implications in development and disease. Mol Pharmacol 76:679-691. CrossRef Medline

Ehninger D, Silva AJ (2011) Rapamycin for treating tuberous sclerosis and autism spectrum disorders. Trends Mol Med 17:78-87. CrossRef Medline

Ehninger D, de Vries PJ, Silva AJ (2009) From mTOR to cognition: molecular and cellular mechanisms of cognitive impairments in tuberous sclerosis. J Intellect Disabil Res 53:838-851. CrossRef Medline

Essrich C, Lorez M, Benson JA, Fritschy JM, Lüscher B (1998) Postsynaptic clustering of major $\mathrm{GABA}_{\mathrm{A}}$ receptor subtypes requires the gamma 2 subunit and gephyrin. Nat Neurosci 1:563-571. CrossRef Medline
Fritschy JM, Harvey RJ, Schwarz G (2008) Gephyrin: where do we stand, where do we go? Trends Neurosci 31:257-264. CrossRef Medline

Graf ER, Zhang X, Jin SX, Linhoff MW, Craig AM (2004) Neurexins induce differentiation of GABA and glutamate postsynaptic specializations via neuroligins. Cell 119:1013-1026. CrossRef Medline

Gross I, Armant O, Benosman S, de Aguilar JL, Freund JN, Kedinger M, Licht JD, Gaiddon C, Loeffler JP (2007) Sprouty2 inhibits BDNF-induced signaling and modulates neuronal differentiation and survival. Cell Death Differ 14:1802-1812. CrossRef Medline

Harvey K, Duguid IC, Alldred MJ, Beatty SE, Ward H, Keep NH, Lingenfelter SE, Pearce BR, Lundgren J, Owen MJ, Smart TG, Lüscher B, Rees MI, Harvey RJ (2004) The GDP-GTP exchange factor collybistin: an essential determinant of neuronal gephyrin clustering. J Neurosci 24:58165826. CrossRef Medline

Hausott B, Vallant N, Schlick B, Auer M, Nimmervoll B, Obermair GJ, Schwarzer C, Dai F, Brand-Saberi B, Klimaschewski L (2012) Sprouty2 and -4 regulate axon outgrowth by hippocampal neurons. Hippocampus 22:434-441. CrossRef Medline

Hetman M, Kanning K, Cavanaugh JE, Xia Z (1999) Neuroprotection by brain-derived neurotrophic factor is mediated by extracellular signalregulated kinase and phosphatidylinositol 3-kinase. J Biol Chem 274: 22569-22580. CrossRef Medline

Holz MK, Blenis J (2005) Identification of S6 kinase 1 as a novel mammalian target of rapamycin (mTOR)-phosphorylating kinase. J Biol Chem 280: 26089-26093. CrossRef Medline

Huttlin EL, Jedrychowski MP, Elias JE, Goswami T, Rad R, Beausoleil SA, Villén J, Haas W, Sowa ME, Gygi SP (2010) A tissue-specific atlas of mouse protein phosphorylation and expression. Cell 143:1174-1189. CrossRef Medline

Jacob TC, Bogdanov YD, Magnus C, Saliba RS, Kittler JT, Haydon PG, Moss SJ (2005) Gephyrin regulates the cell surface dynamics of synaptic $\mathrm{GABA}_{\mathrm{A}}$ receptors. J Neurosci 25:10469-10478. CrossRef Medline

Jin I, Kandel ER, Hawkins RD (2011) Whereas short-term facilitation is presynaptic, intermediate-term facilitation involves both presynaptic and postsynaptic protein kinases and protein synthesis. Learn Mem 18:96102. CrossRef Medline

Jovanovic JN, Thomas P, Kittler JT, Smart TG, Moss SJ (2004) Brainderived neurotrophic factor modulates fast synaptic inhibition by regulating $\mathrm{GABA}_{\mathrm{A}}$ receptor phosphorylation, activity, and cell-surface stability. J Neurosci 24:522-530. CrossRef Medline

Kalscheuer VM, Musante L, Fang C, Hoffmann K, Fuchs C, Carta E, Deas E, Venkateswarlu K, Menzel C, Ullmann R, Tommerup N, Dalprà L, Tzschach A, Selicorni A, Lüscher B, Ropers HH, Harvey K, Harvey RJ (2009) A balanced chromosomal translocation disrupting ARHGEF9 is associated with epilepsy, anxiety, aggression, and mental retardation. Hum Mutat 30:61-68. CrossRef Medline

Kim E, Sheng M (2004) PDZ domain proteins of synapses. Nat Rev Neurosci 5:771-781. CrossRef Medline

Kins S, Betz H, Kirsch J (2000) Collybistin, a newly identified brainspecific GEF, induces submembrane clustering of gephyrin. Nat Neurosci 3:22-29. CrossRef Medline

Kneussel M, Brandstätter JH, Laube B, Stahl S, Muller U, Betz H (1999) Loss of postsynaptic $\mathrm{GABA}_{\mathrm{A}}$ receptor clustering in gephyrin-deficient mice. J Neurosci 19:9289-9297. Medline

Kriebel M, Metzger J, Trinks S, Chugh D, Harvey RJ, Harvey K, Volkmer H (2011) The cell adhesion molecule neurofascin stabilizes axo-axonic GABAergic terminals at the axon initial segment. J Biol Chem 286:2438524393. CrossRef Medline

Kumar V, Zhang MX, Swank MW, Kunz J, Wu GY (2005) Regulation of dendritic morphogenesis by Ras-PI3K-Akt-mTOR and Ras-MAPK signaling pathways. J Neurosci 25:11288-11299. CrossRef Medline

Langosch D, Hoch W, Betz H (1992) The $93 \mathrm{kDa}$ protein gephyrin and tubulin associated with the inhibitory glycine receptor are phosphorylated by an endogenous protein kinase. FEBS Lett 298:113-117. CrossRef Medline

Larsen MH, Mikkelsen JD, Hay-Schmidt A, Sandi C (2010) Regulation of brain-derived neurotrophic factor (BDNF) in the chronic unpredictable stress rat model and the effects of chronic antidepressant treatment. J Psychiatr Res 44:808-816. CrossRef Medline

Luscher B, Fuchs T, Kilpatrick CL (2011) $\mathrm{GABA}_{\mathrm{A}}$ receptor traffickingmediated plasticity of inhibitory synapses. Neuron 70:385-409. CrossRef Medline 
Ma L, Chen Z, Erdjument-Bromage H, Tempst P, Pandolfi PP (2005) Phosphorylation and functional inactivation of TSC2 by Erk implications for tuberous sclerosis and cancer pathogenesis. Cell 121:179-193. CrossRef Medline

Manning BD, Tee AR, Logsdon MN, Blenis J, Cantley LC (2002) Identification of the tuberous sclerosis complex-2 tumor suppressor gene product tuberin as a target of the phosphoinositide 3-kinase/Akt pathway. Mol Cell 10:151-162. CrossRef Medline

Mazzoni A, Broccard FD, Garcia-Perez E, Bonifazi P, Ruaro ME, Torre V (2007) On the dynamics of the spontaneous activity in neuronal networks. PLoS One 2:e439. CrossRef Medline

Medina M, Wandosell F (2011) Deconstructing GSK-3: the fine regulation of its activity. Int J Alzheimers Dis 2011:479249. CrossRef Medline

Minichiello L (2009) TrkB signalling pathways in LTP and learning. Nat Rev Neurosci 10:850-860. CrossRef Medline

Poulopoulos A, Aramuni G, Meyer G, Soykan T, Hoon M, Papadopoulos T, Zhang M, Paarmann I, Fuchs C, Harvey K, Jedlicka P, Schwarzacher SW, Betz H, Harvey RJ, Brose N, Zhang W, Varoqueaux F (2009) Neuroligin 2 drives postsynaptic assembly at perisomatic inhibitory synapses through gephyrin and collybistin. Neuron 63:628-642. CrossRef Medline

Pruss T, Kranz EU, Niere M, Volkmer H (2006) A regulated switch of chick neurofascin isoforms modulates ligand recognition and neurite extension. Mol Cell Neurosci 31:354-365. CrossRef Medline

Quiroga RQ, Nadasdy Z, Ben-Shaul Y (2004) Unsupervised spike detection and sorting with wavelets and superparamagnetic clustering. Neural Comput 16:1661-1687. CrossRef Medline

Rabilloud T (2009) Detergents and chaotropes for protein solubilization before two-dimensional electrophoresis. Methods Mol Biol 528:259-267. CrossRef Medline

Rannals MD, Kapur J (2011) Homeostatic strengthening of inhibitory synapses is mediated by the accumulation of $\mathrm{GABA}_{\mathrm{A}}$ receptors. J Neurosci 30:17701-17712. CrossRef Medline

Reddy-Alla S, Schmitt B, Birkenfeld J, Eulenburg V, Dutertre S, Böhringer C, Götz M, Betz H, Papadopoulos T (2010) PH-domain-driven targeting of collybistin but not Cdc42 activation is required for synaptic gephyrin clustering. Eur J Neurosci 31:1173-1184. CrossRef Medline

Reichardt LF (2006) Neurotrophin-regulated signalling pathways. Philos Trans R Soc Lond B Biol Sci 361:1545-1564. CrossRef Medline

Sabatini DM, Barrow RK, Blackshaw S, Burnett PE, Lai MM, Field ME, Bahr BA, Kirsch J, Betz H, Snyder SH (1999) Interaction of RAFT1 with gephyrin required for rapamycin-sensitive signaling. Science 284:11611164. CrossRef Medline

Saiepour L, Fuchs C, Patrizi A, Sassoè-Pognetto M, Harvey RJ, Harvey K (2010) Complex role of collybistin and gephyrin in $\mathrm{GABA}_{\mathrm{A}}$ receptor clustering. J Biol Chem 285:29623-29631. CrossRef Medline
Seil FJ, Drake-Baumann R (2000) TrkB receptor ligands promote activitydependent inhibitory synaptogenesis. J Neurosci 20:5367-5373. Medline

Soliman GA, Acosta-Jaquez HA, Dunlop EA, Ekim B, Maj NE, Tee AR, Fingar DC (2010) mTOR Ser-2481 autophosphorylation monitors mTORCspecific catalytic activity and clarifies rapamycin mechanism of action. J Biol Chem 285:7866-7879. CrossRef Medline

Sugden PH, Fuller SJ, Weiss SC, Clerk A (2008) Glycogen synthase kinase 3 (GSK3) in the heart: a point of integration in hypertrophic signalling and a therapeutic target? A critical analysis. Br J Pharmacol 153 [Suppl 1]: S137-S153. CrossRef Medline

Tee AR, Anjum R, Blenis J (2003) Inactivation of the tuberous sclerosis complex-1 and -2 gene products occurs by phosphoinositide 3-kinase/ Akt-dependent and -independent phosphorylation of tuberin. J Biol Chem 278:37288-37296. CrossRef Medline

Tyagarajan SK, Ghosh H, Yévenes GE, Nikonenko I, Ebeling C, Schwerdel C, Sidler C, Zeilhofer HU, Gerrits B, Muller D, Fritschy JM (2011a) Regulation of GABAergic synapse formation and plasticity by GSK3betadependent phosphorylation of gephyrin. Proc Natl Acad Sci U S A 108: 379-384. CrossRef Medline

Tyagarajan SK, Ghosh H, Harvey K, Fritschy JM (2011b) Collybistin splice variants differentially interact with gephyrin and $\mathrm{Cdc} 42$ to regulate gephyrin clustering at GABAergic synapses. J Cell Sci 124:2786-2796. CrossRef Medline

Wullschleger S, Loewith R, Hall MN (2006) TOR signaling in growth and metabolism. Cell 124:471-484. CrossRef Medline

Xiang S, Kim EY, Connelly JJ, Nassar N, Kirsch J, Winking J, Schwarz G, Schindelin H (2006) The crystal structure of Cdc42 in complex with collybistin II, a gephyrin-interacting guanine nucleotide exchange factor. J Mol Biol 359:35-46. CrossRef Medline

Xu W (2011) PSD-95-like membrane associated guanylate kinases (PSDMAGUKs) and synaptic plasticity. Curr Opin Neurobiol 21:306-312. CrossRef Medline

Yoshii A, Constantine-Paton M (2010) Postsynaptic BDNF-TrkB signaling in synapse maturation, plasticity, and disease. Dev Neurobiol 70: 304-322. CrossRef Medline

Young W (2009) Review of lithium effects on brain and blood. Cell Transplant 18:951-975. CrossRef Medline

Yu W, Jiang M, Miralles CP, Li RW, Chen G, de Blas AL (2007) Gephyrin clustering is required for the stability of GABAergic synapses. Mol Cell Neurosci 36:484-500. CrossRef Medline

Zita MM, Marchionni I, Bottos E, Righi M, Del Sal G, Cherubini E, Zacchi P (2007) Post-phosphorylation prolyl isomerisation of gephyrin represents a mechanism to modulate glycine receptors function. EMBO J 26: 1761-1771. CrossRef Medline 